\title{
SÍNTESE DE NOVOS 1,2,3-TRIAZÓIS INSPIRADOS NO SRPIN340 E AVALIAÇÃO DE SEUS EFEITOS EM LINHAGEM CELULAR DE GLIOBLASTOMA HUMANO
}

\author{
Sara Maria Ribeiro de Sousa ${ }^{a}$, Róbson Ricardo Teixeira ${ }^{\mathrm{a}, *,(}$, Adilson Vidal Costa $^{\mathrm{b}}$, Alex Ramos de Aguiara, Victor da Rocha \\ Fonseca $^{c}$, Valdemar Lacerda Jr. ${ }^{c}$, Wanderson Romão ${ }^{c}$, Laser Antônio Machado Oliveira ${ }^{d}$, Iára Mariana Lellis Ribeiro ${ }^{d}$, \\ Katiane de Oliveira Pinto Coelho Nogueira ${ }^{d}$, Claudia Jorge do Nascimento ${ }^{e}$ e Jochen Junker ${ }^{f}$ \\ ${ }^{a}$ Departamento de Química, Universidade Federal de Viçosa, 36570-900 Viçosa - MG, Brasil

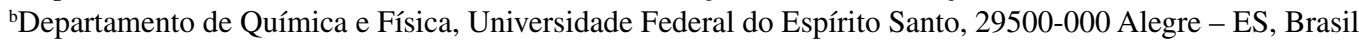 \\ 'Laboratório de Petroleômica e Forense, Universidade Federal do Espírito Santo, 29075-910 Vitória - ES, Brasil \\ ${ }^{\text {d}}$ Departamento de Ciências Biológicas, Instituto de Ciências Exatas e Biológicas, Universidade Federal de Ouro Preto, 35400-000 \\ Ouro Preto - MG, Brasil \\ eDepartamento de Ciências Naturais, Instituto de Biociência, Universidade Federal do Estado do Rio de Janeiro, 22290 -240 Rio \\ de Janeiro - RJ, Brasil \\ ${ }^{\mathrm{f} C e n t r o ~ d e ~ D e s e n v o l v i m e n t o ~ T e c n o l o ́ g i c o ~ e m ~ S a u ́ d e, ~ F u n d a c ̧ a ̃ o ~ O s w a l d o ~ C r u z, ~ 21040-900 ~ R i o ~ d e ~ J a n e i r o ~-~ R J, ~ B r a s i l ~}$
}

Recebido em 06/05/2021; aceito em 16/06/2021; publicado na web em 06/07/2021

\begin{abstract}
SYNTHESIS OF NOVEL 1,2,3-TRIAZOLES INSPIRED ON THE SRPIN340 AND EVALUATION OF THEIR EFFECTS ON HUMAN GLIOBLASTOMA CELL LINE. It is herein described the synthesis of a series of thirty novel 1,2,3-triazole1,4-disubstituted compounds inspired on the known SRPKs inhibitor $N$-(2-(piperidin-1-yl)-5-(trifluoromethyl)phenyl)isonicotinamide (SRPIN340) and biological evaluation of them against human glioblastoma multiforme cell line U87MG. Starting with 1-fluoro2-nitro-4-(trifluoromethyl)benzene (1), the substances were prepared via a five-step synthetic route. The crucial step corresponded to the copper-catalyzed cycloaddition reaction between trifluoromethyl phenyl azides and different alkynes. In general, the compounds were obtained with good yields and they were characterized utilizing spectroscopic (IR and NMR) and spectrometric (HRMS) techniques. The evaluation of the synthesized compounds at three different treatment time $(24 \mathrm{~h}, 48 \mathrm{~h}$, and $72 \mathrm{~h})$ and concentrations $\left(50,100\right.$, and $\left.150 \mu \mathrm{mol} \mathrm{L}^{-1}\right)$ revealed that five derivatives were capable of reducing cell viability by $50 \%$ after $72 \mathrm{~h}$ of treatment at the highest concentration. On the contrary, three derivatives significantly increased cell viability being this effect more pronounced after $48 \mathrm{~h}$ of treatment. In this regard, it stands out the compound 2-((1-(2-morpholino-5-(trifluoromethyl)phenyl)-1 $H$-1,2,3-triazol4-yl)methyl)isoindoline-1,3-dione (7) which increased cell viability in approximately $300 \%$ after $48 \mathrm{~h}$ of treatment at $100 \mu \mathrm{mol} \mathrm{L} \mathrm{L}^{-1}$. The substances that increased cell viaiblity present as common structural features the presence of a saturated nitrogen-containing six-membered ring and carbonylated fragments.
\end{abstract}

Keywords: SRPIN340; 1,2,3-triazole; glioblastoma; U87MG cell line.

\section{INTRODUÇÃO}

O termo câncer (ou neoplasia maligna) relaciona-se a um conjunto de mais de 277 doenças caracterizadas pela perda de capacidade de auto-regulação das células, que passam a se proliferar sem controle. ${ }^{1-4}$ Essas células podem invadir tecidos adjacentes e órgãos à distância por meio do sangue e sistema linfático, originando tumores em outros locais, sendo esse processo denominado metástase. ${ }^{5}$ Esse grupo de doenças apresenta elevada complexidade e representa um importante problema de saúde pública. ${ }^{4} \mathrm{O}$ câncer é a segunda maior causa de mortes no mundo, perdendo apenas para as doenças cardiovasculares, e é reponsável, anualmente, pela morte de dez milhões de pessoas, o que representa uma em cada seis mortes. ${ }^{6,7}$ No Brasil, uma estimativa feita pelo Instituto Nacional de Câncer José Alencar Gomes da Silva (INCA) aponta que, para o biênio 2020-2022, a ocorrência será de 625 mil novos casos de câncer para cada ano. ${ }^{8}$ Os tipos de câncer mais incidentes em homens são próstata $(31,7 \%)$, pulmão $(8,7 \%)$, intestino $(8,1 \%)$, estômago $(6,3 \%)$ e cavidade oral $(5,2 \%)$. Nas mulheres, os cânceres de mama $(29,5 \%)$, intestino $(9,4 \%)$, colo do útero $(8,1 \%)$, pulmão $(6,2 \%)$ e tireoide $(4,0 \%)$ são os mais recorrentes. ${ }^{8}$ As causas relacionadas ao aparecimento do câncer incluem tabagismo, obesidade, fatores ambientais, fatores genéticos, envelhecimento,

*e-mail: robsonr.teixeira@ufv.br dentre outros. ${ }^{4,9}$ Esses fatores concorrem ou se sobrepõe no que tange ao desenvolvimento de cânceres.

Dentre os vários cânceres, os glioblastomas são definidos como tumores de células gliais, que correspondem a células que protegem, nutrem e dão suporte aos neurônios. Esses tumores podem ocorrer no encéfalo, na medula espinhal, ou até mesmo junto a nervos periféricos e são classificados em astrocitomas, oligodendrogliomas, oligoastrocitomas mistos e ependimomas. ${ }^{10}$ Os gliobastomas representam aproximadamente $30 \%$ de todos os tumores do sistema nervoso central e $80 \%$ dos tumores malignos iniciados no cérebro. ${ }^{11,12} \mathrm{O}$ tratamento dos tumores envolve excisão cirúrgica, radioterapia e, para alguns tumores, quimioterapia. A excisão raramente leva à cura, sendo assim necessária a utilização de terapias combinadas. Cumpre ressaltar que o glioblastoma é um tipo de câncer com elevada reincidência. ${ }^{13}$

O desenvolvimento de células cancerosas é um processo multifatorial e um deles está relacionado a alterações na função e na regulação de proteínas conhecidas como proteínas SR (serine arginine rich proteins). ${ }^{14-19}$ A regulação da atividade das proteínas SR, no contexto celular, dá-se por meio da fosforilação extensiva dos resíduos de arginina na porção C-terminal, que pode ser realizada por diferentes famílias de cinases, dentre as quais se destacam as SRPKs (serine arginine protein kinases) ${ }^{20-22}$ Por sua vez, a superexpressão ou desregulação na atividade das SRPKs resultam em respostas celulares inadequadas, que afetam a expressão e/ou splicing alternativo de oncogenes, estando 
diretamente relacionadas à multiplicação celular de vários cânceres,${ }^{20}$ dentre eles o glioblastoma. ${ }^{23}$ Assim, as SRPKs são interessantes alvos moleculares para compostos antitumorais. A substância conhecida como SRPIN340 ( $N$-[2-(piperidin-1-il)-5-(trifluorometil)fenil]-isonicotinamida, Figura 1) é um inibidor ATP-competitivo altamente seletivo na inibição de cinases SRPK1 e SRPK2. ${ }^{24-26}$ Diferentes atividades biológicas têm sido descritas para essa amida e derivados dela, ${ }^{27-34}$ incluindo significativas atividades contra diferentes linhagens de células leucêmicas. ${ }^{35,36}$ e efeitos antimetastáticos ${ }^{37}$ descritas pelo nosso grupo de pesquisa. Afora o SRPIN340, temos também investigado atividades antitumorais de compostos 1,2,3-triazólicos-1,4-dissubstituídos ${ }^{38,39}$ e que vêm sendo sistematicamente estudados com respeito aos seus efeitos antitumorais. ${ }^{40-45}$

Considerando as premissas, vislumbrou-se que compostos resultantes da associação entre uma subunidade 1,2,3-triazol-1,4dissubstituída (destacada em vermelho na Figura 1) e um fragmento trifluorometilfenil apresentando um substituinte nitrogenado na posição 4 em relação ao grupo $\mathrm{CF}_{3}$ (fragmento inspirado no SRPIN340 destacado em azul na Figura 1) poderiam apresentar atividade antitumoral.

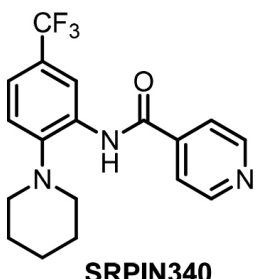

SRPIN340

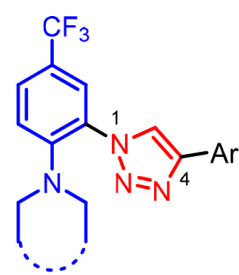

Compostos investigados neste trabalho

\section{$\mathrm{Ar}=$ diferentes grupos aromáticos}

Figura 1. Estrutura do SRPIN340 e dos compostos triazólicos sintetizados e avaliados biologicamente neste trabalho

Assim, o presente trabalho descreve os resultados iniciais com relação à síntese, caracterização e avaliação da atividade em células de glioblastoma U87MG de novos 1,2,3-triazóis-1,4-disubstituídos apresentando a fórmula geral mostrada na Figura 1.

\section{PARTE EXPERIMENTAL}

\section{Generalidades}

Os reagentes utilizados na síntese dos compostos foram todos de grau P.A.

Os compostos 1-fluoro-2-nitro-4-(trifluorometil)benzeno, álcool propargílico, álcool benzílico, álcool 4-clorobenzílico, álcool 4-bromobenzílico, álcool 4-metoxibenzílico, álcool 4-fluorobenzílico, álcool 4-metilbenzílico, álcool 4-trifluorometilbenzílico, ftalimida, brometo de propargila, brometo de tetrabutilamônio, EDC, DMAP, ácido de Meldrum, salicilaldeído, sulfato de cobre pentaidratado, azida de sódio, nitrito de sódio, ascorbato de sódio, morfolina, piperidina, dietilamina e pirrolidina foram adquiridos da Sigma Aldrich (St. Louis, MO, Estados Unidos). O cloreto de estanho(II) pentaidratado e o ácido clorídrico foram adquiridos da F Maia (Charqueada, São Paulo, Brasil). As substâncias diclorometano, acetona, tolueno, dimetilformamida, acetato de etila, metanol e hexano foram adquiridos da Êxodo Científica (Sumaré, São Paulo, Brasil) e da LabSynth (Diadema, São Paulo, Brasil). O carbonato de potássio e o hidróxido de sódio foram adquiridos da LabSynth.

As análises por cromatografia em camada delgada (CCD) foram realizadas utilizando placas cromatográficas de sílica-gel impregnadas sobre alumínio. Após a eluição, as placas de CCD foram observadas em câmera de luz ultravioleta $(\lambda=254 \mathrm{~nm})$ e, quando necessário, reveladas com solução de permanganato de potássio ( $3 \mathrm{~g}$ de $\mathrm{KMnO}_{4}$, $20 \mathrm{~g}$ de $\mathrm{K}_{2} \mathrm{CO}_{3}, 5 \mathrm{~mL}$ de $\mathrm{NaOH} 5 \% \mathrm{~m} \mathrm{v}^{-1}, 300 \mathrm{~mL}$ de água).

As purificações foram realizadas por cromatografia em coluna utilizando sílica-gel (70-230 mesh) como fase estacionária. Os solventes utilizados no preparo dos eluentes foram empregados sem purificação prévia.

As temperaturas de fusão foram determinadas em aparelho MQAPF-302 e não foram corrigidas.

Os espectros no infravermelho (IV) foram adquiridos empregandose a técnica reflectância total atenuada (ATR) em equipamento Varian 660-IR.

Os espectros de ressonância magnética nuclear de hidrogênio (RMN de ${ }^{1} \mathrm{H}, 300 \mathrm{MHz}$ ) e de carbono (RMN de ${ }^{13} \mathrm{C}, 75 \mathrm{MHz}$ ) foram obtidos em espectrômetro Varian MERCURY 300. Os espectros de ressonância magnética nuclear de hidrogênio ( $\mathrm{RMN}$ de ${ }^{1} \mathrm{H}$, $400 \mathrm{MHz}$ ) e de carbono ( $\mathrm{RMN} \mathrm{de}{ }^{13} \mathrm{C}, 100 \mathrm{MHz}$ ) foram adquiridos em espectrômetro Brucker. Os espectros de ressonância magnética nuclear de hidrogênio (RMN de ${ }^{1} \mathrm{H}, 500 \mathrm{MHz}$ ) e de carbono (RMN de ${ }^{13} \mathrm{C}$, $125 \mathrm{MHz}$ ) foram adquiridos em espectrômetro Brucker. Na obtenção dos espectros foram utilizados como solventes deuterados clorofórmio $\left(\mathrm{CDCl}_{3}\right)$ e dimetilsulfóxido (DMSO- $\left.d_{6}\right)$. As constantes de acoplamento escalar $(J)$ foram expressas em Hertz $(\mathrm{Hz})$. As multiplicidades são apresentadas com as seguintes abreviaturas: s (simpleto), sl (simpleto largo), d (dupleto), dd (duplo dupleto), ddtap (duplo duplo tripleto aparente), t (tripleto), q (quarteto), m (multipleto). Os espectros de massas de alta resolução (HRMS) foram adquiridos em espectrômetro de massas 9.4 T Solarix (Bruker Daltonics, Bremen, Germany). As substâncias analisadas 7-36 foram dissolvidas em $1 \mathrm{~mL}$ de acetonitrila. As análises foram realizadas utilizando uma fonte de electrospray no modo positivo de aquição de íons (ESI (+)). Os espectros foram adquiridos em uma faixa de massas $m / z$ de $150-1500$. As condições da fonte de $\operatorname{ESI}(+)$ foram as seguintes: pressão de gás nebulizador de 1,5 bar, voltagem capilar de 4,0-4,4 kV e temperatura do capilar de $250{ }^{\circ} \mathrm{C}$. O tempo de acumulação de íons foi de 0,010-0,040 s, sendo que cada espectro foi adquirido pela acumulação de 16 scans com um domínio de tempo de 4 mega-point. O tempo de voo foi de 0,900 segundo. Todos os espectros de massas foram externamente calibrados utilizando arginina $(\mathrm{m} / \mathrm{z}$ de 150 a 1500$) .{ }^{46} \mathrm{Um}$ poder de resolução, $\mathrm{m} / \Delta \mathrm{m} 50 \%=437,774$ (onde $\Delta \mathrm{m} 50 \%$ corresponde à largura à meia altura do pico de $m / z, 400)^{47,48}$ e uma acurácia $<1 \mathrm{ppm}$ forneceram fórmulas moleculares inequívocas para íons moleculares monocarregados. Os espectros de massas foram processados utilizando o software Data Analysis (Bruker Dantonics, Bremen, Germany). O grau de insaturação para cada molécula foi determinado a partir do seu valor de DBE (double bond equivalent). As composições elementares dos compostos foram determinadas medindo-se os valores de $\mathrm{m} / \mathrm{z}$ (considerando o erro) e os valores de DBE.

\section{Procedimentos sintéticos}

Preparação de nitrocompostos, anilinas, azidas aromáticas e alcinos terminais

Os procedimentos utilizados para a preparação dos nitrocompostos 2a-2d, das anilinas 3a-3d, das azidas 4a-4d, dos alcinos terminais $\mathbf{5 a - 5 h}$ e do composto 6, juntamente com seus dados de caracterização, são apresentados no Material Suplementar.

Sínteses dos compostos triazólicos 7-36 exemplificado pela síntese do composto 2-((1-(2-morfolino-5-(trifluorometilfenil)-1H-1,2,3triazol-4-il)metil) isoindolina-1,3-diona (7)

A um balão de fundo redondo de $50 \mathrm{~mL}$, contendo uma barra de agitação magnética, foram adicionados $0,176 \mathrm{~g}(0,647 \mathrm{mmol})$ 
da azida 4-[2-azido-4-(trifluorometil)fenil] morfolina (4a), 0,100 g (0,540 $\mathbf{m m o l}$ ) do alcino 2-(prop-2-in-1-il) isondolina-1,3-diona (5h), 2,00 mL de álcool $t$-butílico, 2,00 $\mathrm{mL}$ de água destilada, $0,0740 \mathrm{~g}$ $(0,378 \mathrm{mmol}) \mathrm{de}$ ascorbato de sódio e $0,0400 \mathrm{~g}(0,162 \mathrm{mmol}) \mathrm{de}$ sulfato de cobre pentaidratado. A mistura resultante foi mantida sob agitação magnética por $3 \mathrm{~h}$ à temperatura ambiente. Após o término da reação, foram adicionados $10,0 \mathrm{~mL}$ de solução saturada de carbonato de sódio e 10,0 mL de diclorometano. A fase aquosa foi extraída com diclorometano $(4 \times 25,0 \mathrm{~mL})$. Os extratos orgânicos foram combinados e a fase orgânica resultante foi seca com sulfato de sódio anidro, filtrada e concentrada sob pressão reduzida. O produto foi obtido como um sólido amarelo palha, com $70 \%$ de rendimento, purificado por cromatografia em coluna de sílica gel eluída com hexano-acetato de etila $\left(1: 1 \mathrm{v} \mathrm{v}^{-1}\right)$. A estrutura do composto 7 está de acordo com os seguintes dados. P.f. $=179,4-179,9^{\circ} \mathrm{C}, \mathrm{R}_{\mathrm{f}}=0,28$. IV (ATR) $v_{\operatorname{máx}} / \mathrm{cm}^{-1}$ : 3145, 2962, 2956, 2853, 2830, 1770, 1709, 1617, 1516, 1430, 1394, 1331, 1331, 1157, 1114, 1079, 1040, 930, 886, 820, 770, 714, 642, 527. RMN de ${ }^{1} \mathrm{H}\left(400 \mathrm{MHz}, \mathrm{CDCl}_{3}\right) \delta: 2,72(\mathrm{t}, 4 \mathrm{H}, J=4,6 \mathrm{~Hz}) ; 3,62$ (t, 4H, $J=4,6 \mathrm{~Hz}) ; 5,11(\mathrm{~s}, 2 \mathrm{H}) ; 7,22(\mathrm{~d}, 1 \mathrm{H}, J=8,8 \mathrm{~Hz}) ; 7,67(\mathrm{~d}, 1 \mathrm{H}$, $J=8,8 \mathrm{~Hz}) ; 7,74-7,76(\mathrm{~m}, 2 \mathrm{H}) ; 7,79(\mathrm{~d}, 1 \mathrm{H}, J=1,2 \mathrm{~Hz}) ; 7,88-7,90(\mathrm{~m}$, $2 \mathrm{H}) ; 8,31$ (s, $1 \mathrm{H})$. RMN de ${ }^{13} \mathrm{C}\left(100 \mathrm{MHz}, \mathrm{CDCl}_{3}\right) \delta: 32,9 ; 50,8 ; 66,5$; 119,$6 ; 123,4\left(\mathrm{q}, J_{C-F}=270,3 \mathrm{~Hz}\right) ; 123,5 ; 124,3 ; 124,6\left(\mathrm{q}, J_{C-F}=3,7 \mathrm{~Hz}\right)$; $125,5\left(\mathrm{q}, J_{C-F}=33,3 \mathrm{~Hz}\right) ; 127,4\left(\mathrm{q}, J_{C-F}=3,7 \mathrm{~Hz}\right) ; 130,0 ; 131,9 ; 134,3$; 143,$3 ; 148,5 ; 167,6$. HRMS $\left(\mathrm{M}+\mathrm{Na}^{+}\right)$: calculado para $\mathrm{C}_{22} \mathrm{H}_{18} \mathrm{~F}_{3} \mathrm{~N}_{5} \mathrm{NaO}_{3}$ : 480,12540; encontrado: 480,12546. HRMS $\left(2 \mathrm{M}+\mathrm{Na}^{+}\right)$: calculado para $\mathrm{C}_{44} \mathrm{H}_{36} \mathrm{~F}_{6} \mathrm{~N}_{10} \mathrm{NaO}_{6}$ : 937,26157; encontrado: 937,26148.

Os compostos 8-36 foram preparados utilizando a mesma metodologia descrita para a síntese do composto 7. As estruturas desses compostos são suportadas pelos dados apresentados a seguir.

\section{4-(2-(4-((4-clorobenzil)oxi)metil-1H-1,2,3-triazol-1-il)-4-(trifluoro-} metil)fenil) morfolina (8)

Sólido amarelo palha, purificado por cromatografia em coluna de sílica gel eluída com hexano-acetato de etila $\left(2,5: 1 \mathrm{v} \mathrm{v}^{-1}\right)$, P.f. $=84,3-$ $85,3{ }^{\circ} \mathrm{C}, \mathrm{R}_{\mathrm{f}}=0,24$. IV (ATR) $v_{\text {máx }} / \mathrm{cm}^{-1}: 3152,3050,2961,2920,2863$, 2836, 2163, 1621, 1513, 1477, 1450, 1373, 1333, 1321, 1281, 1229, 1157, 1118, 1071, 1040, 1011, 920, 822, 724, 687, 646, 531, 448. $\mathrm{RMN} \mathrm{de}{ }^{1} \mathrm{H}\left(400 \mathrm{MHz}, \mathrm{CDCl}_{3}\right) \delta: 2,74(\mathrm{t}, 4 \mathrm{H}, J=4,6 \mathrm{~Hz}) ; 3,65(\mathrm{t}$, $4 \mathrm{H}, J=4,6 \mathrm{~Hz}) ; 4,63(\mathrm{~s}, 2 \mathrm{H}) ; 4,78(\mathrm{~s}, 2 \mathrm{H}) ; 7,22(\mathrm{~d}, 1 \mathrm{H}, J=8,4 \mathrm{~Hz})$; 7,30-7,35 (m, 4H); 7,69 (dd, $1 \mathrm{H}, J=2,4 \mathrm{~Hz}$ e $J=8,4 \mathrm{~Hz}$ ); 7,83 (d, $1 \mathrm{H}, J=2,4 \mathrm{~Hz}) ; 8,24$ (s, $1 \mathrm{H})$. RMN de ${ }^{13} \mathrm{C}\left(100 \mathrm{MHz}, \mathrm{CDCl}_{3}\right) \delta: 50,8$; 63,$5 ; 66,5 ; 71,7 ; 119,6 ; 123,5$ (q, $\left.J_{C-F}=270,3 \mathrm{~Hz}\right) ; 124,0 ; 124,6$ (q, $\left.J_{C-F}=3,7 \mathrm{~Hz}\right) ; 125,5\left(\mathrm{q}, J_{C-F}=33,7 \mathrm{~Hz}\right) ; 127,4\left(\mathrm{q}, J_{C-F}=3,6 \mathrm{~Hz}\right) ; 128,6$; 129,$0 ; 130,0 ; 133,6 ; 136,2 ; 145,6 ; 148,5$. HRMS $\left(\mathrm{M}+\mathrm{Na}^{+}\right)$: calculado para $\mathrm{C}_{21} \mathrm{H}_{20} \mathrm{ClF}_{3} \mathrm{~N}_{4} \mathrm{NaO}_{2}$ : 475,11191; encontrado: 475,11192. HRMS $\left(2 \mathrm{M}+\mathrm{Na}^{+}\right)$: calculado para $\mathrm{C}_{42} \mathrm{H}_{40} \mathrm{Cl}_{2} \mathrm{~F}_{6} \mathrm{~N}_{8} \mathrm{NaO}_{4}$ : 927,23460; encontrado: 927,23466.

\section{4-(2-(4-(((4-bromobenzil)oxi)metil-1H-1,2,3-triazol-1-il)- 4-(trifluorometil)fenil) morfolina (9)}

Sólido amarelo palha, obtido com $70 \%$ de rendimento, purificado por cromatografia em coluna de sílica gel eluída com hexanoacetato de etila $\left(1: 1 \mathrm{v} \mathrm{v}^{-1}\right)$, P.f. $=89,4-90,0^{\circ} \mathrm{C}, \mathrm{R}_{\mathrm{f}}=0,44$. IV (ATR) $v_{\text {máx }} / \mathrm{cm}^{-1}: 3156,2967,2863,2362,2162,2024,1902,1616,1474$, $1341,1322,1279,1234,1179,1112,1079,1040,1009,920,834$, $820,800,764,647,541,470$. RMN de ${ }^{1} \mathrm{H}\left(400 \mathrm{MHz}, \mathrm{CDCl}_{3}\right) \delta: 2,74$ $(\mathrm{t}, 4 \mathrm{H}, J=4,6 \mathrm{~Hz}) ; 3,65(\mathrm{t}, 4 \mathrm{H}, J=4,6 \mathrm{~Hz}) ; 4,61(\mathrm{~s}, 2 \mathrm{H}) ; 4,78(\mathrm{~s}$, 2H); 7,21-7,27 (m, 3H, H3); 7,49 (d, 2H, $J=8,0 \mathrm{~Hz}) ; 7,69$ (dd, 1H, $J=2,0 \mathrm{~Hz}$ e $J=8,4 \mathrm{~Hz}$ ); 7,83 (d, 1H, $J=2,0 \mathrm{~Hz}) ; 8,24$ (s, 1H). RMN de ${ }^{13} \mathrm{C}\left(100 \mathrm{MHz}, \mathrm{CDCl}_{3}\right) \delta: 50,8 ; 63,5 ; 66,5 ; 71,8 ; 119,6 ; 121,7$; $123,5\left(\mathrm{q}, J_{C-F}=270,0 \mathrm{~Hz}\right) ; 124,0 ; 124,6\left(\mathrm{q}, J_{C-F}=3,7 \mathrm{~Hz}\right) ; 125,5(\mathrm{q}$, $\left.J_{C-F}=33,7 \mathrm{~Hz}\right) ; 127,4\left(\mathrm{q}, J_{C-F}=3,7 \mathrm{~Hz}\right) ; 129,3 ; 130,0 ; 131,6 ; 136,7$;
145,6; 148,5. HRMS $\left(\mathrm{M}+\mathrm{Na}^{+}\right)$: calculado para $\mathrm{C}_{21} \mathrm{H}_{20} \mathrm{BrF}_{3} \mathrm{~N}_{4} \mathrm{NaO}_{2}$ : 519,06139; encontrado: 519,06148. HRMS $\left(2 \mathrm{M}+\mathrm{Na}^{+}\right)$: calculado para $\mathrm{C}_{42} \mathrm{H}_{40} \mathrm{Br}_{2} \mathrm{~F}_{6} \mathrm{~N}_{8} \mathrm{NaO}_{4}$ : 1015,13357; encontrado: 1015,13357.

\section{4-(2-(4-(((4-metoxibenzil)oxi)metil)-1H-1,2,3-triazol-1-il)- 4-(trifluorometil)fenil) morfolina (10)}

Sólido amarelo palha, obtido com $91 \%$ de rendimento, purificado por cromatografia em coluna de sílica gel eluída com hexano-acetato de etila $\left(1: 1 \mathrm{v} \mathrm{v}^{-1}\right)$, P.f. $=97,8-98,7^{\circ} \mathrm{C}, \mathrm{R}_{\mathrm{f}}=0,30 . \mathrm{IV}$ (ATR) $v_{\text {máx }} / \mathrm{cm}^{-1}$ : 3147, 3063, 3042, 2958, 2865, 2361, 2161, 2048, 2016, 1618, 1513, $1475,1451,1343,1321,1281,1233,1168,1114,1079,1028,1007$, 930, 811, 779, 746, 688, 649, 554, 516, 493. RMN de ${ }^{1} \mathrm{H}(400 \mathrm{MHz}$, $\left.\mathrm{CDCl}_{3}\right) \delta: 2,74(\mathrm{t}, 4 \mathrm{H}, J=4,8 \mathrm{~Hz}) ; 3,65(\mathrm{t}, 4 \mathrm{H}, J=4,6 \mathrm{~Hz}) ; 3,81(\mathrm{~s}$, $3 \mathrm{H}) ; 4,59$ (s, 2H); 4,75 (s, 2H); 6,90 (d, 2H, $J=8,8 \mathrm{~Hz}) ; 7,21$ (d, $1 \mathrm{H}, J=8,4 \mathrm{~Hz}) ; 7,31(\mathrm{~d}, 2 \mathrm{H}, J=8,4 \mathrm{~Hz}) ; 7,68(\mathrm{dd}, 1 \mathrm{H}, J=2,0 \mathrm{~Hz}$ e $J=8,4 \mathrm{~Hz}) ; 7,82(\mathrm{~d}, 1 \mathrm{H}, J=2,0 \mathrm{~Hz}) ; 8,22(\mathrm{~s}, 1 \mathrm{H})$. RMN de ${ }^{13} \mathrm{C}$ $\left(100 \mathrm{MHz}, \mathrm{CDCl}_{3}\right) \delta: 50,8 ; 55,3 ; 63,1 ; 66,5 ; 72,3 ; 113,8 ; 119,6$; $123,4\left(\mathrm{q}, J_{C-F}=270,3 \mathrm{~Hz}\right) ; 123,94 ; 124,6\left(\mathrm{q}, J_{C-F}=3,7 \mathrm{~Hz}\right) ; 125,4(\mathrm{q}$, $\left.J_{C-F}=33,3 \mathrm{~Hz}\right) ; 127,25\left(\mathrm{q}, J_{C-F}=3,3 \mathrm{~Hz}\right) ; 129,5 ; 129,7 ; 130,0 ; 146,0$; 148,$5 ; 159,3$. HRMS $\left(\mathrm{M}+\mathrm{Na}^{+}\right)$: calculado para $\mathrm{C}_{22} \mathrm{H}_{23} \mathrm{~F}_{3} \mathrm{~N}_{4} \mathrm{NaO}_{3}$ : 471,16145; encontrado 471,16150. HRMS $\left(2 \mathrm{M}+\mathrm{Na}^{+}\right)$: calculado para $\mathrm{C}_{44} \mathrm{H}_{46} \mathrm{~F}_{6} \mathrm{~N}_{8} \mathrm{NaO}_{6}$ : 919,33367; encontrado: 919,3364.

\section{4-(2-(4-(((benzil)oxi)metil-1H-1,2,3-triazol-1-il)-4-(trifluorometil) fenil) morfolina (11)}

Sólido alaranjado, obtido com $90 \%$ de rendimento, purificado por cromatografia em coluna de sílica gel eluída com hexanoacetato de etila $\left(1: 1 \mathrm{v} \mathrm{v}^{-1}\right)$, P.f. $=76,6-77,1{ }^{\circ} \mathrm{C}, \mathrm{R}_{\mathrm{f}}=0,44$. IV (ATR) $v_{\text {máx }} / \mathrm{cm}^{-1}: 3159,3059,3033,2962,2916,2863,2832,2159,1912,1806$, $1721,1616,1512,1453,1321,1253,1229,1160,1116,1078,1036$, 937, 901, 859, 829, 758, 698, 643, 608, 515. RMN de ${ }^{1} \mathrm{H}(400 \mathrm{MHz}$, $\left.\mathrm{CDCl}_{3}\right) \delta: 2,74(\mathrm{t}, 4 \mathrm{H}, J=4,6 \mathrm{~Hz}) ; 3,65(\mathrm{t}, 4 \mathrm{H}, J=4,6 \mathrm{~Hz}) ; 4,67$ (s, 2H); 4,79 (s, 2H); 7,21 (d, 2H, J = 8,8 Hz); 7,28-7,38 (m, 5H); 7,68 (dd, $1 \mathrm{H}, J=2,0 \mathrm{~Hz}$ e $J=8,4 \mathrm{~Hz}) ; 7,82$ (d, $1 \mathrm{H}, J=2,0 \mathrm{~Hz}$ ); 8,23 (s, 1H). RMN de ${ }^{13} \mathrm{C}\left(100 \mathrm{MHz}, \mathrm{CDCl}_{3}\right) \delta: 50,8 ; 63,5 ; 66,5 ; 72,6 ; 119,6$; $123,5\left(\mathrm{q}, J_{C-F}=270,0 \mathrm{~Hz}\right) ; 123,9 ; 124,6\left(\mathrm{q}, J_{C-F}=3,7 \mathrm{~Hz}\right) ; 125,5(\mathrm{q}$, $\left.J_{C-F}=33,7 \mathrm{~Hz}\right) ; 127,4\left(\mathrm{q}, J_{C-F}=3,7 \mathrm{~Hz}\right) ; 127,7 ; 127,9 ; 128,5 ; 130,1$; 137,$7 ; 145,9 ; 148,5$. HRMS $\left(\mathrm{M}+\mathrm{Na}^{+}\right)$: calculado para $\mathrm{C}_{21} \mathrm{H}_{21} \mathrm{~F}_{3} \mathrm{~N}_{4} \mathrm{NaO}_{3}$ : 441,15088; encontrado 441,15096. HRMS $\left(2 \mathrm{M}+\mathrm{Na}^{+}\right)$: calculado para $\mathrm{C}_{42} \mathrm{H}_{42} \mathrm{~F}_{6} \mathrm{~N}_{8} \mathrm{NaO}_{4}$ : 859,31254; encontrado: 859,31256.

\section{2-(4-(((4-clorobenzil)oxi)metil)-1H-1,2,3-triazol-1-il)-N, $N$-dietil- 4-(trifluorometil) anilina (12)}

Óleo âmbar, obtido com $31 \%$ de rendimento, purificado por cromatografia em coluna de sílica gel eluída com hexano-acetato de etila $\left(2,5: 1 \mathrm{v} \mathrm{v}^{-1}\right), \mathrm{R}_{\mathrm{f}}=0,44$. IV (ATR) $v_{\text {máx }} / \mathrm{cm}^{-1}: 3155,3065,2974$, 2934, 2864, 2159, 2023, 1620, 1513, 1471, 1389, 1323, 1269, 1165, 1117, 1079, 1038, 1013, 896, 806, 721, 677, 658, 610, 536, 477. $\mathrm{RMN} \mathrm{de}{ }^{1} \mathrm{H}\left(400 \mathrm{MHz}, \mathrm{CDCl}_{3}\right) \delta: 0,96(\mathrm{t}, 6 \mathrm{H}, J=7,0 \mathrm{~Hz}) ; 2,87$ (q, $4 \mathrm{H}, J=7,0 \mathrm{~Hz}) ; 4,61$ (s, 2H); 4,77 (s, 2H); 7,22 (d, 1H, $J=8,8 \mathrm{~Hz})$; 7,29-7,34 (m, 4H); 7,61 (dd, 1H, $J=2,2 \mathrm{~Hz}$ e $J=8,6 \mathrm{~Hz}) ; 7,80$ (d, $1 \mathrm{H}, J=2,2 \mathrm{~Hz}) ; 8,14$ (s, $1 \mathrm{H}) . \mathrm{RMN}$ de ${ }^{13} \mathrm{C}\left(100 \mathrm{MHz}, \mathrm{CDCl}_{3}\right) \delta: 11,8$; 45,$4 ; 63,5 ; 71,5 ; 122,14 ; 124,17 ; 123,70\left(\mathrm{q}, J_{C-F}=270,0 \mathrm{~Hz}\right) ; 124,3$ $\left(\mathrm{q}, J_{C-F}=33,3 \mathrm{~Hz}\right) ; 124,7\left(\mathrm{q}, J_{C-F}=4,0 \mathrm{~Hz}\right) ; 126,5\left(\mathrm{q}, J_{C-F}=3,7 \mathrm{~Hz}\right)$; 128,$6 ; 129,1 ; 130,6 ; 133,55 ; 136,3 ; 145,1 ; 147,4$. HRMS $\left(\mathrm{M}+\mathrm{Na}^{+}\right)$: calculado para $\mathrm{C}_{21} \mathrm{H}_{22} \mathrm{ClF}_{3} \mathrm{~N}_{4} \mathrm{NaO}: 461,13264$; encontrado 461,13273. HRMS $\left(2 \mathrm{M}+\mathrm{Na}^{+}\right)$. calculado para $\mathrm{C}_{42} \mathrm{H}_{44} \mathrm{Cl}_{2} \mathrm{~F}_{6} \mathrm{~N}_{8} \mathrm{NaO}_{2}$ : 899,27607; encontrado: 899,27616.

\section{1-(2-(4-(((4-clorobenzil)oxi)metil)-1H-1,2,3-traizol-1-il)- 4-(trifluorometil)fenil) piperidina (13)}

Sólido amarelo, obtido com $69 \%$ de rendimento, purificado por cromatografia em coluna de sílica gel eluída com hexano-acetato 
de etila $\left(4: 1 \mathrm{v} \mathrm{v}^{-1}\right)$, P.f. $=71,4-72,0{ }^{\circ} \mathrm{C}, \mathrm{R}_{\mathrm{f}}=0,37$. IV (ATR) $v_{\text {máx }} / \mathrm{cm}^{-1}: 3106,3067,2982,2932,2863,2812,2749,2160,2026$, 1783, 1646, 1511, 1471, 1321, 1234, 1181, 1125, 1081, 1072, 1041, $888,635,516,485$. RMN de ${ }^{1} \mathrm{H}\left(400 \mathrm{MHz}, \mathrm{CDCl}_{3}\right) \delta: 1,50-1,55$ $(\mathrm{m}, 6 \mathrm{H}) ; 2,70-2,72(\mathrm{~m}, 4 \mathrm{H}) ; 4,62(\mathrm{~s}, 2 \mathrm{H}) ; 4,79(\mathrm{~s}, 2 \mathrm{H}) ; 7,20(\mathrm{~d}, 1 \mathrm{H}$, $J=8,4 \mathrm{~Hz}$ ); 7,32 (s, 4H); 7,63 (dd, 1H, $J=2,2 \mathrm{~Hz}$ e $J=8,6 \mathrm{~Hz}$ ); 7,84 (d, $1 \mathrm{H}, J=2,2 \mathrm{~Hz}) ; 8,31(\mathrm{~s}, 1 \mathrm{H}) . \mathrm{RMN} \mathrm{de}{ }^{13} \mathrm{C}\left(100 \mathrm{MHz}, \mathrm{CDCl}_{3}\right) \delta: 23,7$; 25,$8 ; 51,9 ; 63,5 ; 71,5 ; 120,0 ; 123,6\left(\mathrm{q}, J_{C-F}=270,0 \mathrm{~Hz}\right) ; 124,0 ; 124,1$ $\left(\mathrm{q}, J_{C-F}=3,7 \mathrm{~Hz}\right) ; 124,6\left(\mathrm{q}, J_{C-F}=33,5 \mathrm{~Hz}\right) ; 127,0\left(\mathrm{q}, J_{C-F}=3,7 \mathrm{~Hz}\right)$; 128,$5 ; 129,0 ; 129,9 ; 133,4 ; 136,3 ; 145,2 ; 149,73$. HRMS $\left(\mathrm{M}+\mathrm{Na}^{+}\right)$: calculado para $\mathrm{C}_{22} \mathrm{H}_{22} \mathrm{ClF}_{3} \mathrm{~N}_{4} \mathrm{NaO}$ : 473,13264; encontrado 473,13271. HRMS $\left(2 \mathrm{M}+\mathrm{Na}^{+}\right)$, calculado para $\mathrm{C}_{44} \mathrm{H}_{44} \mathrm{Cl}_{2} \mathrm{~F}_{6} \mathrm{~N}_{8} \mathrm{NaO}_{2}$ : 932,27607; encontrado: 923,27610 .

\section{1-(2-(4-(((4-bromobenzil)oxi)metil)-1H-1,2,3-triazol-1-il)- 4-(trifluorometil)fenil) piperidina (14)}

Sólido amarelo, obtido com $64 \%$ de rendimento, purificado por cromatografia em coluna de sílica gel eluída com hexano-acetato de etila $\left(4: 1 \mathrm{v} \mathrm{v}^{-1}\right)$, P.f. $=66,1-67,2{ }^{\circ} \mathrm{C}, \mathrm{R}_{\mathrm{f}}=0,32$. IV (ATR) $v_{\text {máx }} / \mathrm{cm}^{-1}$ : 3108, 3067, 2982, 2932, 2863, 2822, 2359, 2158, 2017, 1977, 1785, $1723,1620,1511,1468,1450,1320,1231,1179,1119,1080,1046$, $1009,920,860,800,761,702,635,520,502 . \mathrm{RMN}$ de ${ }^{1} \mathrm{H}(400 \mathrm{MHz}$, $\left.\mathrm{CDCl}_{3}\right) \delta: 1,50-1,55(\mathrm{~m}, 6 \mathrm{H}) ; 2,71(\mathrm{t}, 4 \mathrm{H}, J=4,4 \mathrm{~Hz}) ; 4,60(\mathrm{~s}, 2 \mathrm{H})$; 4,79 (s, 2H); 7,20 (d, 1H, $J=8,8 \mathrm{~Hz}) ; 7,25$ (d, 2H, $J=8,4 \mathrm{~Hz}) ; 7,48$ (d, $2 \mathrm{H}, J=8,4 \mathrm{~Hz}$ ); 7,63 (dd, 1H, $J=2,0 \mathrm{~Hz}$ e $J=8,8 \mathrm{~Hz}$ ); 7,84 (d, $1 \mathrm{H}, J=2,0 \mathrm{~Hz}) ; 8,31(\mathrm{~s}, 1 \mathrm{H}) . \mathrm{RMN} \mathrm{de}{ }^{13} \mathrm{C}\left(100 \mathrm{MHz}, \mathrm{CDCl}_{3}\right) \delta: 23,7$; 25,$8 ; 51,9 ; 63,6 ; 71,5 ; 120,0 ; 121,6 ; 123,6\left(\mathrm{q}, J_{C-F}=270,0 \mathrm{~Hz}\right)$; 124,$0 ; 124,1\left(\mathrm{q}, J_{C-F}=4,0 \mathrm{~Hz}\right) ; 124,6\left(\mathrm{q}, J_{C-F}=33,5 \mathrm{~Hz}\right) ; 127,0(\mathrm{q}$, $\left.J_{C-F}=3,7 \mathrm{~Hz}\right) ; 129,3 ; 129,9 ; 131,5 ; 136,9 ; 145,2 ; 149,7$. HRMS $\left(\mathrm{M}+\mathrm{Na}^{+}\right)$: calculado para $\mathrm{C}_{22} \mathrm{H}_{22} \mathrm{BrF}_{3} \mathrm{~N}_{4} \mathrm{NaO}: 517,08213$; encontrado 517,08225. HRMS $\left(2 \mathrm{M}+\mathrm{Na}^{+}\right)$: calculado para $\mathrm{C}_{44} \mathrm{H}_{44} \mathrm{Br}_{2} \mathrm{~F}_{6} \mathrm{~N}_{8} \mathrm{NaO}_{2}$ : 1011,17504; encontrado: 1011,17533.

\section{2-((1-(2-piperidin-1-il)-5-(trifluorometil)fenil)-1H-1,2,3,-triazol- 4-il)metil isoindolina-1,3-diona (15)}

Sólido amarelo, obtido com $70 \%$ de rendimento, purificado por cromatografia em coluna de sílica gel eluída com hexano-acetato de etila $\left(2,5: 1 v^{-1}\right)$, P.f. $=187,5-188,4^{\circ} \mathrm{C}, \mathrm{R}_{\mathrm{f}}=0,30 . \mathrm{IV}($ ATR $) v_{\text {máx }} / \mathrm{cm}^{-1}$ : 3178, 3095, 3059, 2940, 2920, 2857, 2822, 2169, 1766, 1709, 1619, 1512, 1472, 1391, 1327, 1224, 1142, 1107, 1082, 1040, 942, 894, $812,757,709,683,637,527,497 . \mathrm{RMN}$ de ${ }^{1} \mathrm{H}\left(400 \mathrm{MHz}, \mathrm{CDCl}_{3}\right)$ $\delta: 1,38-1,45(\mathrm{~m}, 6 \mathrm{H}) ; 2,67(\mathrm{t}, 4 \mathrm{H}, J=5,2 \mathrm{~Hz}) ; 5,11(\mathrm{sl}, 2 \mathrm{H}) ; 7,17(\mathrm{~d}$, $1 \mathrm{H}, J=8,4 \mathrm{~Hz}) ; 7,60(\mathrm{dd}, 1 \mathrm{H}, J=1,6 \mathrm{~Hz}$ e $J=8,4 \mathrm{~Hz}) ; 7,71-7,76(\mathrm{~m}$, $2 \mathrm{H}) ; 7,79(\mathrm{~d}, 1 \mathrm{H}, J=1,6 \mathrm{~Hz}) ; 7,85-7,90(\mathrm{~m}, 2 \mathrm{H}) ; 8,35$ (s, 1H). RMN de ${ }^{13} \mathrm{C}\left(100 \mathrm{MHz}, \mathrm{CDCl}_{3}\right) \delta: 23,7 ; 25,7 ; 33,0 ; 51,9 ; 120,0 ; 123,4$; $123,6\left(\mathrm{q}, J_{C-F}=270,0 \mathrm{~Hz}\right) ; 124,1\left(\mathrm{q}, J_{C-F}=4,0 \mathrm{~Hz}\right) ; 124,3 ; 124,6(\mathrm{q}$, $\left.J_{C-F}=33,5 \mathrm{~Hz}\right) ; 127,0\left(\mathrm{q}, J_{C-F}=3,7 \mathrm{~Hz}\right) ; 130,0 ; 132,0 ; 134,2 ; 143,1$; 149,$8 ; 167,6$. HRMS $\left(2 \mathrm{M}+\mathrm{Na}^{+}\right)$: calculado para $\mathrm{C}_{46} \mathrm{H}_{40} \mathrm{~F}_{6} \mathrm{~N}_{10} \mathrm{NaO}_{4}$ : 933,30304; encontrado: 933,30298.

\section{1-(2-(4-(((benzil)oxi)metil)-1H-1,2,3-triazol-1-il)-4-(trifluorometil) fenil) piperidina (16)}

Sólido amarelo palha, obtido com $90 \%$ de rendimento, purificado por cromatografia em coluna de sílica gel eluída com hexano-acetato de etila $\left(2,5: 1 \mathrm{v} \mathrm{v}^{-1}\right)$, P.f. $=52,2-53,1{ }^{\circ} \mathrm{C}, \mathrm{R}_{\mathrm{f}}=0,45$. IV (ATR) $v_{\text {máx }} / \mathrm{cm}^{-1}: 3143,3037,2943,2868,2818,2161,1618,1511,1454$, 1344, 1322, 1256, 1125, 1064, 1036, 1015, 899, 816, 745, 697, 638, 518,488 . RMN de ${ }^{1} \mathrm{H}\left(400 \mathrm{MHz}, \mathrm{CDCl}_{3}\right) \delta: 1,46-1,56(\mathrm{~m}, 6 \mathrm{H}) ; 2,71$ (t, 4H, $J=5,0 \mathrm{~Hz}) ; 4,66(\mathrm{~s}, 2 \mathrm{H}) ; 4,81(\mathrm{~s}, 2 \mathrm{H}) ; 7,20(\mathrm{~d}, 1 \mathrm{H}, J=8,4 \mathrm{~Hz})$; 7,27-7,40 (m, 5H); 7,62 (dd, $1 \mathrm{H}, J=2,4 \mathrm{~Hz}$ e $J=8,4 \mathrm{~Hz}) ; 7,83$ (d, $1 \mathrm{H}, J=2,4 \mathrm{~Hz}) ; 8,30(\mathrm{~s}, 1 \mathrm{H}) . \mathrm{RMN} \mathrm{de}{ }^{13} \mathrm{C}\left(100 \mathrm{MHz}, \mathrm{CDCl}_{3}\right) \delta: 23,7$; 25,$8 ; 51,9 ; 63,6 ; 72,4 ; 119,9 ; 123,7$ (q, $\left.J_{C-F}=270,0 \mathrm{~Hz}\right) ; 123,9 ; 124,1$ $\left(\mathrm{q}, J_{C-F}=3,7 \mathrm{~Hz}\right) ; 124,6\left(\mathrm{q}, J_{C-F}=33,5 \mathrm{~Hz}\right) ; 126,9\left(\mathrm{q}, J_{C-F}=3,7 \mathrm{~Hz}\right)$;
127,$7 ; 127,7 ; 128,4 ; 129,9 ; 137,8 ; 145,5 ; 149,7$. HRMS $\left(\mathrm{M}+\mathrm{Na}^{+}\right)$: calculado para $\mathrm{C}_{22} \mathrm{H}_{23} \mathrm{~F}_{3} \mathrm{~N}_{4} \mathrm{NaO}$ : 439,17162; encontrado 439,17174. HRMS $\left(2 \mathrm{M}+\mathrm{Na}^{+}\right)$: calculado para $\mathrm{C}_{44} \mathrm{H}_{46} \mathrm{~F}_{6} \mathrm{~N}_{8} \mathrm{NaO}_{2}: 855,35401$; encontrado: 855,35402 .

\section{1-(2-(4-(((4-metoxibenzil)oxi)metil)-1H-1,2,3-triazol-1-il)- 4-(trifluorometil)fenil) piperidina (17)}

Sólido amarelo palha, obtido com $90 \%$ de rendimento, purificado por cromatografia em coluna de sílica gel eluída com hexano-acetato de etila $\left(2,5: 1 \mathrm{v} \mathrm{v}^{-1}\right)$, P.f. $=92,7-93,7{ }^{\circ} \mathrm{C}, \mathrm{R}_{\mathrm{f}}=0,38$. IV (ATR) $v_{\text {máx }} / \mathrm{cm}^{-1}: 3127,3085,2934,2853,2833,2164,2059,1982,1798$, 1617, 1511, 1466, 1380, 1327, 1236, 1166, 1143, 1114, 1026, 921, $899,833,738,634,571,518,450 . \mathrm{RMN}$ de ${ }^{1} \mathrm{H}\left(400 \mathrm{MHz}, \mathrm{CDCl}_{3}\right)$ $\delta: 1,49-1,56$ (m, 6H, H4'); 2,71 (t, 4H, $J=4,0 \mathrm{~Hz}) ; 3,81$ (s, 3H); 4,59 (sl, 2H); 4,77 (sl, 2H); 6,87-6,91 (m, 2H); 7,20 (d, 1H, J=8,8 Hz); 7,29-7,32 (m, 2H); 7,62 (dd, 1H, $J=1,6 \mathrm{~Hz}$ e $J=8,4 \mathrm{~Hz}$ ); 7,83 (d, 1H, $J=2,0 \mathrm{~Hz}) ; 8,28(\mathrm{sl}, 1 \mathrm{H})$. RMN de ${ }^{13} \mathrm{C}\left(100 \mathrm{MHz}, \mathrm{CDCl}_{3}\right) \delta: 23,8$; 25,$9 ; 52,0 ; 5,3 ; 63,3 ; 72,1 ; 113,8 ; 120,0 ; 123,7$ (q, $\left.J_{C-F}=270,0 \mathrm{~Hz}\right)$; 123,$9 ; 124,2\left(\mathrm{q}, J_{C-F}=4,0 \mathrm{~Hz}\right) ; 124,9\left(\mathrm{q}, J_{C-F}=33,5 \mathrm{~Hz}\right) ; 127,0(\mathrm{q}$, $\left.J_{C-F}=3,6 \mathrm{~Hz}\right) ; 129,5 ; 129,9 ; 130,0 ; 145,6 ; 149,8 ; 159,3$. HRMS $\left(2 \mathrm{M}+\mathrm{Na}^{+}\right)$: calculado para $\mathrm{C}_{46} \mathrm{H}_{50} \mathrm{~F}_{6} \mathrm{~N}_{8} \mathrm{NaO}_{4}$ : 915,37514 ; encontrado: 915,37520 .

\section{$N, N$-dietil-2-(4-((4-metoxibenzil)oxi)metil)-1H-1,2,3-triazol-1-il)- 4-(trifluorometil)anilina (18)}

Sólido amarelo palha, obtido com $76 \%$ de rendimento, purificado por cromatografia em coluna de sílica gel eluída com hexanoacetato de etila $\left(3: 1 \mathrm{v} \mathrm{v}^{-1}\right)$, P.f. $=54,0-55,1^{\circ} \mathrm{C}, \mathrm{R}_{\mathrm{f}}=0,32$. IV (ATR) $v_{\text {máx }} / \mathrm{cm}^{-1}: 3115,3080,2974,2938,2843,2160,2031,1619,1515$, 1472, 1370, 1325, 1276, 1243, 1167, 1120, 1088, 1032, 894, 822, 782, 722, 679, 613, 555, 516, 447. RMN de ${ }^{1} \mathrm{H}\left(400 \mathrm{MHz}, \mathrm{CDCl}_{3}\right)$ $\delta: 0,96(\mathrm{t}, 6 \mathrm{H}, J=7,0 \mathrm{~Hz}) ; 2,72(\mathrm{q}, 4 \mathrm{H}, J=7,1 \mathrm{~Hz}) ; 3,81(\mathrm{~s}, 1 \mathrm{H})$; $4,58(\mathrm{~s}, 2 \mathrm{H}) ; 4,75$ (s, 2H); 6,89 (d, 2H, $J=8,4 \mathrm{~Hz}) ; 7,21$ (d, 1H, $J=8,4 \mathrm{~Hz}) ; 7,30$ (d, 2H, $J=8,4 \mathrm{~Hz}) ; 7,61(\mathrm{dd}, 1 \mathrm{H}, J=1,8 \mathrm{~Hz}$ e $J=8,6 \mathrm{~Hz}) ; 7,80(\mathrm{~d}, 1 \mathrm{H}, J=2,0 \mathrm{~Hz}) ; 8,12(\mathrm{~s}, 1 \mathrm{H})$. RMN de ${ }^{13} \mathrm{C}$ $\left(100 \mathrm{MHz}, \mathrm{CDCl}_{3}\right) \delta: 11,9 ; 45,5 ; 55,3 ; 63,2 ; 72,1 ; 113,9 ; 122,1$; $123,7\left(\mathrm{q}, J_{C-F}=269,7 \mathrm{~Hz}\right) ; 124,1 ; 124,2\left(\mathrm{q}, J_{C-F}=33,5 \mathrm{~Hz}\right) ; 124,8(\mathrm{q}$, $\left.J_{C-F}=4,0 \mathrm{~Hz}\right) ; 126,5\left(\mathrm{q}, J_{C-F}=3,7 \mathrm{~Hz}\right) ; 129,6 ; 129,9 ; 130,7 ; 145,5$; 147,$4 ; 159,4$. HRMS $\left(\mathrm{M}+\mathrm{Na}^{+}\right)$: calculado para $\mathrm{C}_{22} \mathrm{H}_{25} \mathrm{~F}_{3} \mathrm{~N}_{4} \mathrm{NaO}_{2}$ : 457,18218; encontrado 457,18231. HRMS $\left(2 \mathrm{M}+\mathrm{Na}^{+}\right)$: calculado para $\mathrm{C}_{44} \mathrm{H}_{50} \mathrm{~F}_{6} \mathrm{~N}_{8} \mathrm{NaO}_{4}$ : 891,37514; encontrado: 891,37529.

\section{2-((1-(2-(dietilamino)-5-(trifluorometil)fenil)-1H-1,2,3-triazol-4-il) metil)isoindolina-1,3-diona (19)}

Óleo amarelo, obtido com $76 \%$ de rendimento, purificado por cromatografia em coluna de sílica gel eluída com hexano-acetato de etila $\left(2,5: 1 \mathrm{v} \mathrm{v}^{-1}\right), \mathrm{R}_{\mathrm{f}}=0,20$. IV (ATR) $v_{\text {máx }} / \mathrm{cm}^{-1}: 3148,3066,2974$, 2935, 2874, 2161, 1773, 1713, 1619, 1514, 1469, 1428, 1390, 1324, $1269,1166,1115,1081,1040,936,896,825,761,712,678,608,529$, 457. RMN de ${ }^{1} \mathrm{H}\left(400 \mathrm{MHz}, \mathrm{CDCl}_{3}\right) \delta: 0,94$ (t, $\left.6 \mathrm{H}, J=7,0 \mathrm{~Hz}\right) ; 2,84$ (q, $4 \mathrm{H}, J=7,2 \mathrm{~Hz}) ; 5,09$ (s, 1H); 7,19 (d, 1H, $J=8,4 \mathrm{~Hz}) ; 7,59$ (dd, 1H, $J=1,8 \mathrm{~Hz}$ e $J=8,6 \mathrm{~Hz}) ; 7,72-7,76(\mathrm{~m}, 3 \mathrm{H}) ; 7,86-7,88(\mathrm{~m}, 2 \mathrm{H}) ; 8,19$ (s, $1 \mathrm{H})$. $\mathrm{RMN}$ de ${ }^{13} \mathrm{C}\left(100 \mathrm{MHz}, \mathrm{CDCl}_{3}\right) \delta: 11,8 ; 33,0 ; 45,3 ; 122,1 ; 123,5$; $123,7\left(\mathrm{q}, J_{C-F}=269,7 \mathrm{~Hz}\right) ; 124,1\left(\mathrm{q}, J_{C-F}=33,5 \mathrm{~Hz}\right) ; 124,5 ; 124,7$ (q, $\left.J_{C-F}=4,0 \mathrm{~Hz}\right) ; 126,5\left(\mathrm{q}, J_{C-F}=3,3 \mathrm{~Hz}\right) ; 130,4 ; 132,5 ; 134,2 ; 142,9$; 147,6; 167,7. HRMS $\left(\mathrm{M}+\mathrm{Na}^{+}\right)$: calculado para $\mathrm{C}_{22} \mathrm{H}_{20} \mathrm{~F}_{3} \mathrm{~N}_{5} \mathrm{NaO}_{2}$ : 466,14613; encontrado 466,14628. HRMS $\left(2 \mathrm{M}+\mathrm{Na}^{+}\right)$: calculado para $\mathrm{C}_{44} \mathrm{H}_{40} \mathrm{~F}_{6} \mathrm{~N}_{10} \mathrm{NaO}_{4}$ : 909,30304; encontrado: 909,30310.

\section{2-((1-(2-(pirrolidin-1-il)-5-(trifluorometil)fenil)-1H-1,2,3-triazol- 4-il)metil)isoindolina-1,3-diona (20)}

Sólido amarelo, obtido com $77 \%$ de rendimento, purificado por cromatografia em coluna de sílica gel eluída com hexano-acetato de 
etila $\left(3: 2 \mathrm{v} \mathrm{v}^{-1}\right)$, P.f. $=172,4-172,9^{\circ} \mathrm{C}, \mathrm{R}_{\mathrm{f}}=0,28$. IV (ATR) $v_{\text {máx }} / \mathrm{cm}^{-1}$ : 3136, 3089, 2978, 2954, 2873, 2362, 2161, 2010, 1766, 1708, 1621, 1560, 1527, 1470, 1433, 1394, 1324, 1274, 1231, 1177, 1149, 1100, 1084, 1042, 1020, 938, 896, 854, 804, 766, 715, 667, 648, 612, 529, 500, 483. RMN de ${ }^{1} \mathrm{H}\left(400 \mathrm{MHz}, \mathrm{CDCl}_{3}\right) \delta: 1,76-1,81(\mathrm{~m}, 4 \mathrm{H}) ; 2,88$ (t, 4H, $J=6,4 \mathrm{~Hz}) ; 5,09$ (s, 2H); 6,84 (d, 1H, $J=8,8 \mathrm{~Hz}) ; 7,37$ (d, $1 \mathrm{H}, J=2,0 \mathrm{~Hz}) ; 7,51(\mathrm{dd}, 1 \mathrm{H}, J=2,0 \mathrm{~Hz}$ e $J=8,8 \mathrm{~Hz}) ; 7,73-7,75$ (m, 2H); 7,82 (s, 1H); 7,87-7,89 (m, 2H). RMN de ${ }^{13} \mathrm{C}(100 \mathrm{MHz}$, $\left.\mathrm{CDCl}_{3}\right) \delta: 25,4 ; 33,1 ; 48,9 ; 115,3 ; 118,0\left(\mathrm{q}, J_{C-F}=33,7 \mathrm{~Hz}\right) ; 121,6$; 123,$6 ; 124,1\left(\mathrm{q}, J_{C-F}=269,0 \mathrm{~Hz}\right) ; 126,9 ; 127,0\left(\mathrm{q}, J_{C-F}=4,0 \mathrm{~Hz}\right)$; 127,7 (q, $\left.J_{C-F}=3,3 \mathrm{~Hz}\right) ; 132,0 ; 134,2 ; 142,8 ; 146,5 ; 167,7$. HRMS $\left(\mathrm{M}+\mathrm{Na}^{+}\right)$: calculado para $\mathrm{C}_{22} \mathrm{H}_{18} \mathrm{~F}_{3} \mathrm{~N}_{5} \mathrm{NaO}_{2}$ : 464,13048; encontrado 464,13055 . HRMS $\left(2 \mathrm{M}+\mathrm{Na}^{+}\right.$): calculado para $\mathrm{C}_{44} \mathrm{H}_{36} \mathrm{~F}_{6} \mathrm{~N}_{10} \mathrm{NaO}_{4}$ : 905,27174; encontrado: 905,27187.

\section{2-((1-(2-(pirrolidin-1-il)-5-(trifluorometil)fenil)-1H-1,2,3-triazol-}

4-il)metil)isoindolina-1,3-diona (21)

Sólido amarelo palha, obtido com $68 \%$ de rendimento, purificado por cromatografia em coluna de sílica gel eluída com hexanoacetato de etila $\left(3: 2 \mathrm{v} \mathrm{v}^{-1}\right)$, P.f. $=50,6-51,2{ }^{\circ} \mathrm{C}, \mathrm{R}_{\mathrm{f}}=0,44$. IV (ATR) $v_{\text {máx }} / \mathrm{cm}^{-1}:$ 3140, 3082, 2969, 2897, 2853, 2161, 2008, 1617, 1514, 1464, 1414, 1374, 1322, 1277, 1250, 1225, 1147, 1097, 1069, 1037, $1002,956,914,855,827,805,772,705,649,576,521,485$. RMN de ${ }^{1} \mathrm{H}\left(400 \mathrm{MHz}, \mathrm{CDCl}_{3}\right) \delta: 1,79-1,82(\mathrm{~m}, 4 \mathrm{H}) ; 2,92(\mathrm{t}, 4 \mathrm{H}, J=6,6 \mathrm{~Hz})$; $3,81(\mathrm{~s}, 3 \mathrm{H}) ; 4,59(\mathrm{~s}, 2 \mathrm{H}) ; 4,75(\mathrm{~s}, 2 \mathrm{H}) ; 6,86(\mathrm{~d}, 1 \mathrm{H}, J=8,8 \mathrm{~Hz})$; 6,88-6,91 (m, 2H); 7,28-7,32 (m, 2H); 7,38 (d, 1H, $J=2,0 \mathrm{~Hz})$; 7,54 (dd, $1 \mathrm{H}, J=2,0 \mathrm{~Hz}$ e $J=8,8 \mathrm{~Hz}$ ); 7,76 (s, 1H,). RMN de ${ }^{13} \mathrm{C}$ $\left(100 \mathrm{MHz}, \mathrm{CDCl}_{3}\right) \delta: 25,4 ; 48,9 ; 55,3 ; 63,3 ; 72,3 ; 113,9 ; 115,3$; $118,0\left(\mathrm{q}, J_{C-F}=33,7 \mathrm{~Hz}\right) ; 121,7 ; 124,1\left(\mathrm{q}, J_{C-F}=268,7 \mathrm{~Hz}\right) ; 126,6$; $127,0\left(\mathrm{q}, J_{C-F}=4,0 \mathrm{~Hz}\right) ; 127,7\left(\mathrm{q}, J_{C-F}=3,7 \mathrm{~Hz}\right) ; 129,6 ; 129,8 ; 145,5$; 146,$5 ; 159,4$. HRMS $\left(\mathrm{M}+\mathrm{Na}^{+}\right)$: calculado para $\mathrm{C}_{22} \mathrm{H}_{23} \mathrm{~F}_{3} \mathrm{~N}_{4} \mathrm{NaO}_{2}$ : 455,16653; encontrado 455,16668. HRMS $\left(2 \mathrm{M}+\mathrm{Na}^{+}\right)$. calculado para $\mathrm{C}_{44} \mathrm{H}_{46} \mathrm{~F}_{6} \mathrm{~N}_{8} \mathrm{NaO}_{4}$ : 887,34384; encontrado: 887,34399.

\section{4-(((4-bromobenzil)oxi)metil)-1-(2-(pirrolidin-1-il)-5-(trifluoro- metil)fenil)-1H-1,2,3-triazol (22)}

Sólido marrom claro, obtido com $71 \%$ de rendimento, purificado por cromatografia em coluna de sílica gel eluída com hexanoacetato de etila $\left(3: 2 \mathrm{v} \mathrm{v}^{-1}\right)$, P.f. $=83,1-84,0{ }^{\circ} \mathrm{C}, \mathrm{R}_{\mathrm{f}}=0,50$. IV (ATR) $v_{\text {máx }} / \mathrm{cm}^{-1}: 3145,3067,2968,2951,2898,2855,2158,2022,1798$, $1619,1525,1486,1470,1410,1375,1322,1274,1247,1142,1099$, 1071, 1041, 1002, 954, 901, 846, 801, 764, 702, 647, 579, 513. RMN de ${ }^{1} \mathrm{H}\left(400 \mathrm{MHz}, \mathrm{CDCl}_{3}\right) \delta: 1,79-1,82(\mathrm{~m}, 4 \mathrm{H}) ; 2,91(\mathrm{t}, 4 \mathrm{H}$, $J=6,4 \mathrm{~Hz}) ; 4,61(\mathrm{~s}, 2 \mathrm{H}) ; 4,77(\mathrm{~s}, 2 \mathrm{H}) ; 6,86(\mathrm{~d}, 1 \mathrm{H}, J=8,8 \mathrm{~Hz})$; $7,49$ (d, 2H, $J=8,4 \mathrm{~Hz}) ; 7,39$ (d, 1H, $J=1,6 \mathrm{~Hz}) ; 7,47-7,50(\mathrm{~m}$, $2 \mathrm{H}) ; 7,54(\mathrm{dd}, 1 \mathrm{H}, J=2,0 \mathrm{~Hz}$ e $J=8,8 \mathrm{~Hz}) ; 7,78(\mathrm{~s}, 1 \mathrm{H})$. RMN de ${ }^{13} \mathrm{C}\left(100 \mathrm{MHz}, \mathrm{CDCl}_{3}\right) \delta: 25,4 ; 49,0 ; 63,7 ; 71,8 ; 115,3 ; 118,1$ (q, $\left.J_{C-F}=33,7 \mathrm{~Hz}\right) ; 121,7 ; 121,8 ; 124,1\left(\mathrm{q}, J_{C-F}=268,7 \mathrm{~Hz}\right) ; 126,6$; $127,0\left(\mathrm{q}, J_{C-F}=4,0 \mathrm{~Hz}\right) ; 127,7\left(\mathrm{q}, J_{C-F}=3,7 \mathrm{~Hz}\right) ; 129,5 ; 131,6 ; 136,8$; 145,$1 ; 146,5$. HRMS $\left(\mathrm{M}+\mathrm{Na}^{+}\right)$: calculado para $\mathrm{C}_{21} \mathrm{H}_{20} \mathrm{BrF}_{3} \mathrm{~N}_{4} \mathrm{NaO}$ : 503,06648; encontrado 503,0660 HRMS $\left(2 \mathrm{M}+\mathrm{Na}^{+}\right)$: calculado para $\mathrm{C}_{42} \mathrm{H}_{40} \mathrm{Br}_{2} \mathrm{~F}_{6} \mathrm{~N}_{8} \mathrm{NaO}_{2}$ : 983,14374; encontrado: 983,14398.

4-(((benzil)oxi)metil)-1-(2-(pirrolidin-1-il)-5-(trifluorometil)fenil)1H-1,2,3-triazol (23)

Óleo amarelo, obtido com $36 \%$ de rendimento, purificado por cromatografia em coluna de sílica gel eluída com hexano-acetato de etila $\left(2: 1 \mathrm{v} \mathrm{v}^{-1}\right), \mathrm{R}_{\mathrm{f}}=0,40$. IV (ATR) $v_{\text {max }} / \mathrm{cm}^{-1}: 3140,3064,3032$, 2970, 2870, 2159, 2007, 1718, 1621, 1563, 1525, 1456, 1374, 1324, 1273, 1249, 1150, 1106, 1081, 1040, 956, 898, 810, 736, 698, 648, 603, 537, 502, 485. RMN de ${ }^{1} \mathrm{H}\left(400 \mathrm{MHz}, \mathrm{CDCl}_{3}\right) \delta: 1,79-1,82(\mathrm{~m}$, $4 \mathrm{H}) ; 1,92(\mathrm{t}, 4 \mathrm{H}, J=6,6 \mathrm{~Hz}) ; 4,66(\mathrm{~s}, 2 \mathrm{H}) ; 4,79(\mathrm{~s}, 2 \mathrm{H},) ; 6,86(\mathrm{~d}, 1 \mathrm{H}$, $J=9,2 \mathrm{~Hz}) ; 7,29-7,38(\mathrm{~m}, 5 \mathrm{H}) ; 7,54(\mathrm{dd}, 1 \mathrm{H}, J=2,2 \mathrm{~Hz}$ e $J=9,0 \mathrm{~Hz})$;
7,77 (s, 1H). RMN de ${ }^{13} \mathrm{C}\left(100 \mathrm{MHz}, \mathrm{CDCl}_{3}\right) \delta: 25,4 ; 48,9 ; 63,7 ; 72,7$; 115,$3 ; 118,0\left(\mathrm{q}, J_{C-F}=33,7 \mathrm{~Hz}\right) ; 121,7 ; 124,2\left(\mathrm{q}, J_{C-F}=268,3 \mathrm{~Hz}\right)$; 126,$6 ; 127,0\left(\mathrm{q}, J_{C-F}=4,0 \mathrm{~Hz}\right) ; 127,7$ (q, $\left.J_{C-F}=3,3 \mathrm{~Hz}\right) ; 127,9 ; 128,5$; 137,$7 ; 145,4 ; 146,5$. HRMS $\left(\mathrm{M}+\mathrm{Na}^{+}\right)$: calculado para $\mathrm{C}_{21} \mathrm{H}_{21} \mathrm{~F}_{3} \mathrm{~N}_{4} \mathrm{NaO}$ : 425,15597; encontrado 425,15604. HRMS $\left(2 \mathrm{M}+\mathrm{Na}^{+}\right)$: calculado para $\mathrm{C}_{42} \mathrm{H}_{42} \mathrm{~F}_{6} \mathrm{~N}_{8} \mathrm{NaO}_{2}$ : 827,32271; encontrado: 827,32292.

\section{4-(((4-clorobenzil)oxi)metil)-1-(2-(pirrolidin-1-il)-5-(trifluoro- metil)fenil)-1H-1,2,3-triazol (24)}

Sólido amarelo, obtido com $53 \%$ de rendimento, purificado por cromatografia em coluna de sílica gel eluída com hexano-acetato de etila $\left(2: 1 \mathrm{v} \mathrm{v}^{-1}\right)$, P.f. $=69,7-70,5^{\circ} \mathrm{C}, \mathrm{R}_{\mathrm{f}}=0,36$. IV (ATR) $v_{\text {max }} / \mathrm{cm}^{-1}$ : 3142, 2970, 2929, 2869, 2160, 2030, 1900, 1721, 1621, 1563, 1524, 1489, 1463, 1374, 1324, 1272, 1249, 1150, 1108, 1081, 1040, 1014, 957, 898, 807, 765, 705, 649, 536, 485. RMN de ${ }^{1} \mathrm{H}(400 \mathrm{MHz}$, $\left.\mathrm{CDCl}_{3}\right) \delta: 1,79-1,82(\mathrm{~m}, 4 \mathrm{H}) ; 2,91(\mathrm{t}, 4 \mathrm{H}, J=6,4 \mathrm{~Hz}) ; 4,62(\mathrm{~s}, 2 \mathrm{H})$; 4,77 (s, 2H); 6,86 (d, 1H, $J=9,2 \mathrm{~Hz}) ; 7,30-7,35$ (m, 4H); 7,39 (d, $1 \mathrm{H}, J=2,0 \mathrm{~Hz}) ; 7,54(\mathrm{dd}, 1 \mathrm{H}, J=1,8 \mathrm{~Hz}$ e $J=9,0 \mathrm{~Hz}) ; 7,78(\mathrm{~s}, 1 \mathrm{H})$. $\mathrm{RMN} \mathrm{de}{ }^{13} \mathrm{C}\left(100 \mathrm{MHz}, \mathrm{CDCl}_{3}\right) \delta: 25,4 ; 49,0 ; 63,6 ; 71,8 ; 115,3 ; 118,1$ $\left(\mathrm{q}, J_{C-F}=33,7 \mathrm{~Hz}\right) ; 121,7 ; 124,1\left(\mathrm{q}, J_{C-F}=268,7 \mathrm{~Hz}\right) ; 126,6 ; 127,0(\mathrm{q}$, $\left.J_{C-F}=4,0 \mathrm{~Hz}\right) ; 127,7\left(\mathrm{q}, J_{C-F}=3,3 \mathrm{~Hz}\right) ; 128,7 ; 129,2 ; 133,6 ; 136,2$; 145,$1 ; 145,5$. HRMS $\left(\mathrm{M}+\mathrm{Na}^{+}\right)$: calculado para $\mathrm{C}_{21} \mathrm{H}_{20} \mathrm{ClF}_{3} \mathrm{~N}_{4} \mathrm{NaO}$ : 459,11699; encontrado 459,11711. HRMS $\left(2 \mathrm{M}+\mathrm{Na}^{+}\right)$. calculado para $\mathrm{C}_{42} \mathrm{H}_{40} \mathrm{Cl}_{2} \mathrm{~F}_{6} \mathrm{~N}_{8} \mathrm{NaO}_{2}$ : 895,24477; encontrado: 895,24501.

\section{4-(2-(4-((4-fluorobenzil)oxi)metil)-1H-1,2,3-triazol-1-il)- \\ 4-(trifluorometil)fenil)morfolina (25)}

Sólido amarelo palha, obtido com $72 \%$ de rendimento, purificado por cromatografia em coluna de sílica gel eluída com hexano-acetato de etila $\left(3: 2 \mathrm{v} \mathrm{v}^{-1}\right)$, P.f. $=71,5-72,4{ }^{\circ} \mathrm{C}, \mathrm{R}_{\mathrm{f}}=0,34$. IV (ATR) $v_{\text {maxx }} / \mathrm{cm}^{-1}$ : 3151, 3074, 2963, 2857, 2160, 2029, 1730, 1621, 1511, 1473, 1453, 1375, 1323, 1280, 1223, 1162, 1114, 1081, 1039, 932, 922, 898, 823, 777, 688, 646, 566, 401. RMN de ${ }^{1} \mathrm{H}\left(500 \mathrm{MHz}, \mathrm{CDCl}_{3}\right) \delta: 2,77(\mathrm{t}$, $4 \mathrm{H}, J=4,5 \mathrm{~Hz}) ; 3,67(\mathrm{t}, 4 \mathrm{H}, J=4,5 \mathrm{~Hz}) ; 4,65(\mathrm{~s}, 2 \mathrm{H}) ; 4,80(\mathrm{~s}, 2 \mathrm{H})$; 7,05-7,09 (m, 2H); 7,23 (d, 1H, $J=8,5 \mathrm{~Hz}) ; 7,36-7,39$ (m, 2H); 7,71 (dd, $1 \mathrm{H}, J=3,0 \mathrm{~Hz}$ e $J=8,5 \mathrm{~Hz}) ; 7,84(\mathrm{~d}, 1 \mathrm{H}, J=1,5 \mathrm{~Hz}) ; 8,25$ (s, $1 \mathrm{H}) . \mathrm{RMN}$ de ${ }^{13} \mathrm{C}\left(125 \mathrm{MHz}, \mathrm{CDCl}_{3}\right) \delta: 50,9 ; 63,5 ; 66,6 ; 71,9 ; 115,4$ $\left(\mathrm{d}, J_{C-F}=21,3 \mathrm{~Hz}\right) ; 119,7 ; 124,0 ; 124,6\left(\mathrm{q}, J_{C-F}=270,0 \mathrm{~Hz}\right) ; 125,2(\mathrm{q}$, $\left.J_{C-F}=3,8 \mathrm{~Hz}\right) ; 125,6\left(\mathrm{q}, J_{C-F}=33,8 \mathrm{~Hz}\right) ; 127,5\left(\mathrm{q}, J_{C-F}=3,3 \mathrm{~Hz}\right) ; 129,6$ $\left(\mathrm{d}, J_{C-F}=7,5 \mathrm{~Hz}\right) ; 130,1 ; 133,5\left(\mathrm{~d}, J_{C-F}=2,5 \mathrm{~Hz}\right) ; 145,8 ; 148,6 ; 162,5$ $\left(\mathrm{d}, J_{C-F}=243,8 \mathrm{~Hz}\right)$. HRMS $\left(\mathrm{M}+\mathrm{Na}^{+}\right)$: calculado para $\mathrm{C}_{21} \mathrm{H}_{20} \mathrm{~F}_{4} \mathrm{~N}_{4} \mathrm{NaO}_{2}$ : 459,14146; encontrado 459,14157. HRMS $\left(2 \mathrm{M}+\mathrm{Na}^{+}\right)$: calculado para $\mathrm{C}_{42} \mathrm{H}_{40} \mathrm{~F}_{8} \mathrm{~N}_{8} \mathrm{NaO}_{4}$ : 895,29370; encontrado: 895,29390.

\section{4-(4-(trifluorometil)-2-(4-(((4-(trifluorometil)benzil)oxi)metil)- 1H-1,2,3-triazol-1-il)fenil)morfolina (26)}

Sólido amarelo palha, obtido com $72 \%$ de rendimento, purificado por cromatografia em coluna de sílica gel eluída com hexanoacetato de etila $\left(3: 2 \mathrm{v} \mathrm{v}^{-1}\right)$, P.f. $=78,2-78,9{ }^{\circ} \mathrm{C}, \mathrm{R}_{\mathrm{f}}=0,25$. IV (ATR) $v_{\text {máx }} / \mathrm{cm}^{-1}: 3151,3049,2963,2862,2160,2035,1621,1515,1478$, 1449, 1415, 1376, 1321, 1283, 1230, 1160, 1110, 1065, 1040, 1011, 930, 919, 850, 827, 689, 644, 596, 506. RMN de ${ }^{1} \mathrm{H}(500 \mathrm{MHz}$, $\left.\mathrm{CDCl}_{3}\right) \delta: 2,77(\mathrm{t}, 4 \mathrm{H}, J=4,5 \mathrm{~Hz}) ; 3,67(\mathrm{t}, 4 \mathrm{H}, J=4,5 \mathrm{~Hz}) ; 4,75(\mathrm{~s}$, $2 \mathrm{H}) ; 4,83(\mathrm{~s}, 2 \mathrm{H}) ; 7,24(\mathrm{~d}, 1 \mathrm{H}, J=8,5 \mathrm{~Hz}) ; 7,52(\mathrm{~d}, J=8,0 \mathrm{~Hz}) ; 7,65$ $(\mathrm{d}, J=8,5 \mathrm{~Hz}) ; 7,71(\mathrm{dd}, 1 \mathrm{H}, J=2,0 \mathrm{~Hz}$ e $J=8,5 \mathrm{~Hz}) ; 7,85$ (d, $1 \mathrm{H}$, $J=2,5 \mathrm{~Hz}) ; 8,27$ (s, 1H). RMN de ${ }^{13} \mathrm{C}\left(125 \mathrm{MHz}, \mathrm{CDCl}_{3}\right) \delta: 50,9$; 63,$8 ; 66,6 ; 71,7 ; 119,7 ; 123,5\left(\mathrm{q}, J_{C-F}=270,4 \mathrm{~Hz}\right) ; 124,1 ; 124,1(\mathrm{q}$, $\left.J_{C-F}=270,4 \mathrm{~Hz}\right) ; 124,7\left(\mathrm{q}, J_{C-F}=3,75 \mathrm{~Hz}\right) ; 125,5\left(\mathrm{q}, J_{C-F}=3,75 \mathrm{~Hz}\right)$; $125,9\left(\mathrm{q}, J_{C-F}=33,5 \mathrm{~Hz}\right) ; 127,5\left(\mathrm{q}, J_{C-F}=3,3 \mathrm{~Hz}\right) ; 127,6 ; 130,0$ $\left(\mathrm{q}, J_{C-F}=32,1 \mathrm{~Hz}\right) ; 130,1 ; 141,9 ; 145,6 ; 148,6$. HRMS $\left(\mathrm{M}+\mathrm{Na}^{+}\right)$: calculado para $\mathrm{C}_{22} \mathrm{H}_{20} \mathrm{~F}_{6} \mathrm{~N}_{4} \mathrm{NaO}_{2}$ : 509,13827; encontrado 509,13840. HRMS $\left(2 \mathrm{M}+\mathrm{Na}^{+}\right)$: calculado para $\mathrm{C}_{44} \mathrm{H}_{40} \mathrm{~F}_{12} \mathrm{~N}_{8} \mathrm{NaO}_{4}$ : 995,28731; encontrado: 995,28753. 


\section{4-((4-fluorobenzil)oxi)metil)-1-(2-(pirrolidin-1-il)-5-(trifluoro-} metil)fenil)-1H-1,2,3-triazol (27)

Sólido amarelo palha, obtido com $55 \%$ de rendimento, purificado por cromatografia em coluna de sílica gel eluída com hexanoacetato de etila $\left(3: 2 \mathrm{v} \mathrm{v}^{-1}\right)$, P.f. $=68,9-69,7^{\circ} \mathrm{C}, \mathrm{R}_{\mathrm{f}}=0,38$. IV (ATR) $v_{\text {máx }} / \mathrm{cm}^{-1}:$ 3133, 3096, 3049, 2976, 2951, 2869, 2849, 2810, 2162, 2030, 1735, 1620, 1601, 1562, 1510, 1461, 1414, 1361, 1331, 1314, 1282, 1223, 1149, 1110, 1066, 1043, 1014, 927, 814, 789, 697, 642, 564, 495. RMN de ${ }^{1} \mathrm{H}\left(500 \mathrm{MHz}, \mathrm{CDCl}_{3}\right) \delta: 1,81-1,84$ (m, 4H); 2,94 $(\mathrm{t}, 4 \mathrm{H}, J=6,8 \mathrm{~Hz}) ; 4,64$ (s, 2H); 4,79 (s, 2H); 6,88 (d, 1H, $J=9,0 \mathrm{~Hz})$; 7,04-7,09 (m, 2H); 7,35-7,39 (m, 2H); 7,41 (d, 1H, $J=2,0 \mathrm{~Hz})$; 7,57 (dd, $1 \mathrm{H}, J=2,5 \mathrm{~Hz}$ e $J=9,0 \mathrm{~Hz}$ ); 7,98 (s, 1H). RMN de ${ }^{13} \mathrm{C}$ $\left(125 \mathrm{MHz}, \mathrm{CDCl}_{3}\right) \delta: 25,4 ; 48,9 ; 63,6 ; 71,9 ; 115,4\left(\mathrm{~d}, J_{C-F}=21,3 \mathrm{~Hz}\right)$; 115,$4 ; 118,1\left(\mathrm{q}, J_{C-F}=33,8 \mathrm{~Hz}\right) ; 122,0 ; 124,1\left(\mathrm{q}, J_{C-F}=268,8 \mathrm{~Hz}\right) ;$ 126,$6 ; 127,0\left(\mathrm{q}, J_{C-F}=3,75 \mathrm{~Hz}\right) ; 127,7\left(\mathrm{q}, J_{C-F}=3,3 \mathrm{~Hz}\right) ; 129,7$ $\left(\mathrm{d}, J_{C-F}=8,8 \mathrm{~Hz}\right) ; 133,5\left(\mathrm{~d}, J_{C-F}=3,8 \mathrm{~Hz}\right) ; 145,2 ; 146,5 ; 162,5(\mathrm{~d}$, $\left.J_{C-F}=245,0 \mathrm{~Hz}\right)$. HRMS $\left(\mathrm{M}+\mathrm{Na}^{+}\right)$: calculado para $\mathrm{C}_{21} \mathrm{H}_{20} \mathrm{~F}_{4} \mathrm{~N}_{4} \mathrm{NaO}$ : 443,14655; encontrado 443,14666. HRMS $\left(2 \mathrm{M}+\mathrm{Na}^{+}\right)$. calculado para $\mathrm{C}_{42} \mathrm{H}_{40} \mathrm{~F}_{8} \mathrm{~N}_{8} \mathrm{NaO}_{2}$ : 863,30387; encontrado: 863,30395.

\section{1-(2-(pirrolidin-1-il)-5-(trifluorometil)fenil)-4-((4-(trifluorometil) benzil)oxi)metil)-1H-1,2,3-triazol (28)}

Óleo amarelo, obtido com $59 \%$ de rendimento, purificado por cromatografia em coluna de sílica gel eluída com hexano-acetato de etila $\left(3: 2 \mathrm{v} \mathrm{v}^{-1}\right), \mathrm{R}_{\mathrm{f}}=0,34$. IV (ATR) $v_{\text {maxx }} / \mathrm{cm}^{-1}: 3136,2972,2873$, 2362, 2160, 2032, 1621, 1563, 1525, 1464, 1374, 1322, 1273, 1250, 1152, 1106, 1064, 1040, 1017, 956, 899, 811, 768, 705, 642, 593, 500. RMN de ${ }^{1} \mathrm{H}\left(500 \mathrm{MHz}, \mathrm{CDCl}_{3}\right) \delta: 1,81-1,84(\mathrm{~m}, 4 \mathrm{H}) ; 2,92-$ $2,95(\mathrm{~m}, 4 \mathrm{H}) ; 4,74$ (s, 2H); 4,82 (s, 2H); 6,89 (d, 1H, J = 9,0 Hz); $7,42(\mathrm{~d}, 1 \mathrm{H}, J=2,5 \mathrm{~Hz}) ; 7,52(\mathrm{~d}, 2 \mathrm{H}, J=8,0 \mathrm{~Hz}) ; 7,57(\mathrm{dd}, 1 \mathrm{H}$, $J=2,5 \mathrm{~Hz}$ e $J=9,0 \mathrm{~Hz}) ; 7,64(\mathrm{~d}, 2 \mathrm{H}, J=8,0 \mathrm{~Hz}) ; 7,82(\mathrm{~s}, 1 \mathrm{H})$. $\mathrm{RMN}$ de ${ }^{13} \mathrm{C}\left(125 \mathrm{MHz}, \mathrm{CDCl}_{3}\right) \delta: 25,4 ; 49,0 ; 63,9 ; 71,7 ; 115,4$; $118,1\left(\mathrm{q}, J_{C-F}=33,8 \mathrm{~Hz}\right) ; 121,7 ; 124,1\left(\mathrm{q}, J_{C-F}=269,6 \mathrm{~Hz}\right) ; 125,4$ $\left(\mathrm{q}, J_{C-F}=3,8 \mathrm{~Hz}\right) ; 126,6 ; 126,9\left(\mathrm{q}, J_{C-F}=3,8 \mathrm{~Hz}\right) ; 127,7 ; 127,8(\mathrm{q}$, $\left.J_{C-F}=2,5 \mathrm{~Hz}\right) ; 130,0\left(\mathrm{q}, J_{C-F}=32,5 \mathrm{~Hz}\right) ; 141,9 ; 144,9 ; 146,6$. HRMS $\left(\mathrm{M}+\mathrm{Na}^{+}\right)$: calculado para $\mathrm{C}_{22} \mathrm{H}_{20} \mathrm{~F}_{6} \mathrm{~N}_{4} \mathrm{NaO}$ : 493,14335; encontrado 493,14349. HRMS $\left(2 \mathrm{M}+\mathrm{Na}^{+}\right)$: calculado para $\mathrm{C}_{44} \mathrm{H}_{40} \mathrm{~F}_{12} \mathrm{~N}_{8} \mathrm{NaO}_{2}$ : 963,29748; encontrado: 963,29771.

\section{1-(2-(4-(((4-fluorobenzil)oxi)metil)-1H-1,2,3-triazol-1-il)- 4-(trifluorometil)fenil)piperidina (29)}

Óleo laranja, obtido com $86 \%$ de rendimento, purificado por cromatografia em coluna de sílica gel eluída com hexano-acetato de etila $\left(2: 1 \mathrm{v} \mathrm{v}^{-1}\right), \mathrm{R}_{\mathrm{f}}=0,58$. IV (ATR) $v_{\text {máx }} / \mathrm{cm}^{-1}: 3153,3070,2938$, 2857, 2818, 2160, 2032, 1620, 1510, 1470, 1382, 1322, 1275, 1222, 1168, 1118, 1080, 1038, 1014, 921, 897, 820, 776, 685, 637, 567, 519,499 . RMN de ${ }^{1} \mathrm{H}\left(500 \mathrm{MHz}, \mathrm{CDCl}_{3}\right) \delta: 1,48-1,57(\mathrm{~m}, 6 \mathrm{H})$; $2,74(\mathrm{t}, 4 \mathrm{H}, J=5,0 \mathrm{~Hz}) ; 4,64(\mathrm{~s}, 2 \mathrm{H}) ; 4,81(\mathrm{~s}, 2 \mathrm{H}) ; 7,04-7,08(\mathrm{~m}$, $2 \mathrm{H}) ; 7,22(\mathrm{~d}, 1 \mathrm{H}, J=8,5 \mathrm{~Hz}) ; 7,36-7,38(\mathrm{~m}, 2 \mathrm{H}) ; 7,65(\mathrm{dd}, 1 \mathrm{H}$, $J=2,0 \mathrm{~Hz}$ e $J=9,0 \mathrm{~Hz}) ; 7,86(\mathrm{~d}, 1 \mathrm{H}, J=2,0 \mathrm{~Hz}) ; 8,32(\mathrm{~s}, 1 \mathrm{H})$. RMN de ${ }^{13} \mathrm{C}\left(125 \mathrm{MHz}, \mathrm{CDCl}_{3}\right) \delta: 23,8 ; 25,9 ; 52,0 ; 63,5 ; 71,6 ; 115,3(\mathrm{~d}$, $\left.J_{C-F}=21,3 \mathrm{~Hz}\right) ; 120,0 ; 123,7\left(\mathrm{q}, J_{C-F}=270,0 \mathrm{~Hz}\right) ; 124,0 ; 124,2(\mathrm{q}$, $\left.J_{C-F}=3,8 \mathrm{~Hz}\right) ; 124,7\left(\mathrm{q}, J_{C-F}=33,3 \mathrm{~Hz}\right) ; 127,0\left(\mathrm{q}, J_{C-F}=3,8 \mathrm{~Hz}\right)$; $129,5\left(\mathrm{~d}, J_{C-F}=7,5 \mathrm{~Hz}\right) ; 130,0 ; 133,7\left(\mathrm{~d}, J_{C-F}=3,8 \mathrm{~Hz}\right) ; 145,3$; 149,$8 ; 162,4\left(\mathrm{~d}, J_{C-F}=245,0 \mathrm{~Hz}\right)$. HRMS $\left(\mathrm{M}+\mathrm{Na}^{+}\right)$: calculado para $\mathrm{C}_{22} \mathrm{H}_{22} \mathrm{~F}_{4} \mathrm{~N}_{4} \mathrm{NaO}$ : 457,16220; encontrado 457,16229. HRMS $\left(2 \mathrm{M}+\mathrm{Na}^{+}\right)$. calculado para $\mathrm{C}_{44} \mathrm{H}_{44} \mathrm{~F}_{8} \mathrm{~N}_{8} \mathrm{NaO}_{2}:$ : 891,33517; encontrado: 891,33522 .

\section{1-(4-(trifluorometil)-2-(4-(((4-(trifluorometil)benzil)oxi)metil)- 1H-1,2,3-triazol-1-il)fenil)piperidina (30)}

Óleo laranja, obtido com $44 \%$ de rendimento, purificado por cromatografia em coluna de sílica gel eluída com hexano-acetato de etila $\left(2: 1 \mathrm{v} \mathrm{v}^{-1}\right), \mathrm{R}_{\mathrm{f}}=0,67$. IV (ATR) $v_{\text {maxx }} / \mathrm{cm}^{-1}: 3157,3070,2940$, 2858, 2819, 2363, 2160, 2032, 1621, 1514, 1471, 1383, 1321, 1276, 1237, 1163, 1115, 1065, 1039, 1017, 921, 898, 821, 767, 725, 686, $637,593,519$. RMN de ${ }^{1} \mathrm{H}\left(500 \mathrm{MHz}, \mathrm{CDCl}_{3}\right) \delta: 1,51-1,59(\mathrm{~m}, 6 \mathrm{H})$; $2,75(\mathrm{t}, 4 \mathrm{H}, J=4,8 \mathrm{~Hz}) ; 4,74(\mathrm{~s}, 2 \mathrm{H}) ; 4,87(\mathrm{~s}, 2 \mathrm{H}) ; 7,25(\mathrm{~d}, 1 \mathrm{H}$, $J=8,5 \mathrm{~Hz}) ; 7,51(\mathrm{~d}, 2 \mathrm{H}, J=8,0 \mathrm{~Hz}) ; 7,64(\mathrm{~d}, 2 \mathrm{H}, J=8,0 \mathrm{~Hz}) ; 7,78$ (dd, $1 \mathrm{H}, J=1,5 \mathrm{~Hz}$ e $J=8,5 \mathrm{~Hz}) ; 7,86(\mathrm{~d}, 1 \mathrm{H}, J=1,5 \mathrm{~Hz}) ; 8,38$ (s, $1 \mathrm{H}) . \mathrm{RMN}$ de ${ }^{13} \mathrm{C}\left(125 \mathrm{MHz}, \mathrm{CDCl}_{3}\right) \delta: 23,8 ; 25,9 ; 52,0 ; 63,7$; 71,$6 ; 120,1 ; 124,2$ (q, $\left.J_{C-F}=3,8 \mathrm{~Hz}\right) ; 124,7$ (q, $\left.J_{C-F}=270,6 \mathrm{~Hz}\right)$; $125,0\left(\mathrm{q}, J_{C-F}=33,3 \mathrm{~Hz}\right) ; 125,4\left(J_{C-F}=3,8 \mathrm{~Hz}\right) ; 127,2 ; 127,6 ; 141,9$; 145,$0 ; 149,8$. HRMS $\left(\mathrm{M}+\mathrm{Na}^{+}\right)$: calculado para $\mathrm{C}_{23} \mathrm{H}_{22} \mathrm{~F}_{6} \mathrm{~N}_{4} \mathrm{NaO}$ : 507,15900; encontrado 507,15906. HRMS $\left(2 \mathrm{M}+\mathrm{Na}^{+}\right)$. calculado para $\mathrm{C}_{46} \mathrm{H}_{44} \mathrm{~F}_{12} \mathrm{~N}_{8} \mathrm{NaO}_{2}$ : 991,32878; encontrado: 991,32889.

\section{4-(2-(4-(((4-metilbenzil)oxi)metil)-1H-1,2,3-triazol-1-il)- \\ 4-(trifluorometil)fenil)morfolina (31)}

Sólido amarelo palha, obtido com $64 \%$ de rendimento, purificado por cromatografia em coluna de sílica gel eluída com hexano-acetato de etila $\left(3: 2 \mathrm{v} \mathrm{v}^{-1}\right)$, P.f. $=77,3-78,1^{\circ} \mathrm{C}, \mathrm{R}_{\mathrm{f}}=0,39$. IV (ATR) $v_{\text {máx }} / \mathrm{cm}^{-1}$ : 3142, 2960, 2894, 2856, 2160, 2025, 1735, 1621, 1515, 1473, 1453, 1375, 1323, 1280, 1233, 1163, 1114, 1081, 1038, 1019, 932, 921, 897, $823,803,749,687,645,569,539,483 . \mathrm{RMN} \mathrm{de}{ }^{1} \mathrm{H}\left(500 \mathrm{MHz}, \mathrm{CDCl}_{3}\right)$ $\delta: 2,37(\mathrm{~s}, 3 \mathrm{H}) ; 2,75-2,77(\mathrm{~m}, 4 \mathrm{H}) ; 3,66-3,68(\mathrm{~m}, 4 \mathrm{H}) ; 4,64(\mathrm{~s}, 2 \mathrm{H})$; 4,79 (s, 2H); 7,19-7,30 (m, 5H); 7,70 (dd, $J=2,0 \mathrm{~Hz}$ e $J=8,5 \mathrm{~Hz})$; $7,84(\mathrm{~d}, 1 \mathrm{H}, J=2,0 \mathrm{~Hz}) ; 8,24(\mathrm{~s}, 1 \mathrm{H}) . \mathrm{RMN}$ de ${ }^{13} \mathrm{C}\left(125 \mathrm{MHz}, \mathrm{CDCl}_{3}\right)$ $\delta: 21,2 ; 50,9 ; 63,4 ; 66,6 ; 72,6 ; 119,6 ; 123,5\left(\mathrm{q}, J_{C-F}=270,0 \mathrm{~Hz}\right)$; 123,$9 ; 124,7\left(\mathrm{q}, J_{C-F}=3,8 \mathrm{~Hz}\right) ; 125,5\left(\mathrm{q}, J_{C-F}=33,8 \mathrm{~Hz}\right) ; 127,4(\mathrm{q}$, $\left.J_{C-F}=3,3 \mathrm{~Hz}\right) ; 127,9 ; 129,2 ; 130,1 ; 134,7 ; 137,6 ; 146,1 ; 148,6$. HRMS $\left(\mathrm{M}+\mathrm{Na}^{+}\right)$: calculado para $\mathrm{C}_{22} \mathrm{H}_{23} \mathrm{~F}_{3} \mathrm{~N}_{4} \mathrm{NaO}_{2}: 455,16653$; encontrado 455,16663 . HRMS $\left(2 \mathrm{M}+\mathrm{Na}^{+}\right)$: calculado para $\mathrm{C}_{44} \mathrm{H}_{46} \mathrm{~F}_{6} \mathrm{~N}_{8} \mathrm{NaO}_{4}$ : 887,34384; encontrado: 887,34396.

4-(((4-metilbenzil)oxi)metil)-1-(2-(pirrolidin-1-il)-5-(trifluorometil) fenil)-1H-1,2,3-triazol (32)

Sólido amarelo palha, obtido com $74 \%$ de rendimento, purificado por cromatografia em coluna de sílica gel eluída com hexano-acetato de etila $\left(3: 2 \mathrm{v} \mathrm{v}^{-1}\right)$, P.f. $=77,3-78,9^{\circ} \mathrm{C}, \mathrm{R}_{\mathrm{f}}=0,53$. IV (ATR) $v_{\text {máx }} / \mathrm{cm}^{-1}$ : 3136, 2973, 2952, 2895, 2855, 2161, 1782, 1620, 1558, 1525, 1471, 1413, 1376, 1323, 1273, 1247, 1229, 1145, 1099, 1072, 1041, 1000, 955, 894, 853, 803, 772, 754, 701, 649, 569, 535, 491. RMN de ${ }^{1} \mathrm{H}$ $\left(500 \mathrm{MHz}, \mathrm{CDCl}_{3}\right) \delta: 1,82-1,84(\mathrm{~m}, 4 \mathrm{H}) ; 2,37(\mathrm{~s}, 3 \mathrm{H}) ; 2,94(\mathrm{t}, 4 \mathrm{H}$, $J=6,5 \mathrm{~Hz}) ; 4,64(\mathrm{~s}, 2 \mathrm{H}) ; 4,78(\mathrm{~s}, 2 \mathrm{H}) ; 6,88(\mathrm{~d}, 1 \mathrm{H}, J=8,5 \mathrm{~Hz}) ; 7,19$ $(\mathrm{d}, J=8,0 \mathrm{~Hz}, 2 \mathrm{H}) ; 7,27(\mathrm{~d}, J=8,0 \mathrm{~Hz}, 2 \mathrm{H}) ; 7,41(\mathrm{~d}, 1 \mathrm{H}, J=2,0 \mathrm{~Hz})$; $7,56(\mathrm{dd}, 1 \mathrm{H}, J=2,0 \mathrm{~Hz}$ e $J=9,0 \mathrm{~Hz}) ; 7,78(\mathrm{~s}, 1 \mathrm{H})$. RMN de ${ }^{13} \mathrm{C}$ $\left(125 \mathrm{MHz}, \mathrm{CDCl}_{3}\right) \delta: 21,2 ; 25,4 ; 48,9 ; 63,5 ; 72,6 ; 115,3 ; 118,1$ (q, $\left.J_{C-F}=33,8 \mathrm{~Hz}\right) ; 121,7 ; 124,2\left(\mathrm{q}, J_{C-F}=268,8 \mathrm{~Hz}\right) ; 126,5 ; 127,0(\mathrm{q}$, $\left.J_{C-F}=4,2 \mathrm{~Hz}\right) ; 127,7\left(\mathrm{q}, J_{C-F}=3,8 \mathrm{~Hz}\right) ; 128,0 ; 129,2 ; 134,7 ; 137,7$; 145,$5 ; 146,6$. HRMS $\left(\mathrm{M}+\mathrm{Na}^{+}\right)$: calculado para $\mathrm{C}_{22} \mathrm{H}_{23} \mathrm{~F}_{3} \mathrm{~N}_{4} \mathrm{NaO}$ : 439,17162 encontrado 439,17175 .

\section{1-(2-(4-(((4-metilbenzil)oxi)metil)-1H-1,2,3-triazol-1-il)- 4-(trifluorometil)fenil)piperidina (33)}

Óleo laranja, obtido com $86 \%$ de rendimento, purificado por cromatografia em coluna de sílica gel eluída com hexano-acetato de etila $\left(3: 1 \mathrm{v} \mathrm{v}^{-1}\right), \mathrm{R}_{\mathrm{f}}=0,42$. IV (ATR) $v_{\text {máx }} / \mathrm{cm}^{-1}: 3147,3053,2937$, 2856, 2817, 2160, 2029, 1620, 1513, 1470, 1382, 1322, 1274, 1236, 1167, 1118, 1080, 1038, 1023, 921, 896, 803, 769, 749, 685, 662, 570, 519, 483. RMN de ${ }^{1} \mathrm{H}\left(500 \mathrm{MHz}, \mathrm{CDCl}_{3}\right) \delta: 1,51-1,56(\mathrm{~m}, 6 \mathrm{H})$; 2,37 (s, 3H); 2,74 (t, 4H, J = 5,0 Hz); 4,64 (s, 2H); 4,80 (s, 2H); 7, 187,30 (m, 5H); 7,65 (dd, $1 \mathrm{H}, J=1,5 \mathrm{~Hz}$ e $J=8,5 \mathrm{~Hz}) ; 7,85$ (d, $1 \mathrm{H}$, $J=2,0 \mathrm{~Hz}) ; 8,30$ (s, 1H). RMN de ${ }^{13} \mathrm{C}\left(125 \mathrm{MHz}, \mathrm{CDCl}_{3}\right) \delta: 21,2 ; 23,8$; 25,$9 ; 52,0 ; 63,4 ; 72,3 ; 120,0 ; 123,9 ; 122,6\left(\mathrm{q}, J_{C-F}=270,0 \mathrm{~Hz}\right) ; 124,4$ $\left(\mathrm{q}, J_{C-F}=3,8 \mathrm{~Hz}\right) ; 124,8\left(\mathrm{q}, J_{C-F}=33,8 \mathrm{~Hz}\right) ; 127,0\left(\mathrm{q}, J_{C-F}=3,8 \mathrm{~Hz}\right)$; 
127,$9 ; 129,1 ; 130,0 ; 134,8 ; 137,5 ; 145,6 ; 149,8$. HRMS (M+Na+): calculado para $\mathrm{C}_{23} \mathrm{H}_{25} \mathrm{~F}_{3} \mathrm{~N}_{4} \mathrm{NaO}$ : 453,18727; encontrado 453,18735. HRMS $\left(2 \mathrm{M}+\mathrm{Na}^{+}\right)$: calculado para $\mathrm{C}_{46} \mathrm{H}_{50} \mathrm{~F}_{6} \mathrm{~N}_{8} \mathrm{NaO}_{2}$ : 883,38531; encontrado: 883,38540 .

\section{(1-(2-morfolina-5-(trifluorometil)fenil)-1H-1,2,3-triazol-4-il)metil} 2-oxo-2H-benzopirano-3-carboxilato (34)

Sólido amarelo palha, obtido com $90 \%$ de rendimento, purificado por cromatografia em coluna de sílica gel eluída com acetato de etila-hexano $\left(2: 1 \mathrm{v} \mathrm{v}^{-1}\right)$, P.f. $=171,3-173,9^{\circ} \mathrm{C}, \mathrm{R}_{\mathrm{f}}=0,38$. IV (ATR) $v_{\text {máx }} / \mathrm{cm}^{-1}: 3156,3063,2974,2855,2361,2162,2024,1977,1739$, $1711,1607,1563,1517,1460,1375,1327,1301,1266,1239$, 1208, 1186, 1161, 1110, 1080, 1033, 973, 924, 905, 839, 794, 763, 724, 641, 587, 539, 508, 459. RMN de ${ }^{1} \mathrm{H}\left(400 \mathrm{MHz}, \mathrm{CDCl}_{3}\right)$ $\delta: 2,76(\mathrm{t}, 4 \mathrm{H}, J=4,6 \mathrm{~Hz}) ; 3,87(\mathrm{t}, 4 \mathrm{H}, J=4,6 \mathrm{~Hz}) ; 5,62(\mathrm{~s}, 2 \mathrm{H})$; 7,25 (d, 1H, $J=8,4 \mathrm{~Hz})$; 7,35-7,39 (m, 2H); 7,63-7,72 (m, 3H); $7,85$ (d, $1 \mathrm{H}, J=1,6 \mathrm{~Hz}) ; 8,53$ (s, 1H); 8,63 (s, 1H). RMN de ${ }^{13} \mathrm{C}$ $\left(100 \mathrm{MHz}, \mathrm{CDCl}_{3}\right) \delta: 50,9 ; 58,9 ; 66,5 ; 116,9 ; 117,2 ; 117,7 ; 119,8$; $123,5\left(\mathrm{q}, J_{C-F}=270,0 \mathrm{~Hz}\right) ; 124,6\left(\mathrm{q}, J_{C-F}=3,7 \mathrm{~Hz}\right) ; 125,1 ; 125,6$ $\left(\mathrm{q}, J_{C-F}=34,0 \mathrm{~Hz}\right) ; 125,8 ; 127,6\left(\mathrm{q}, J_{C-F}=3,7 \mathrm{~Hz}\right) ; 129,7 ; 130,0$; 134,$9 ; 143,1 ; 148,6 ; 149,6 ; 155,3 ; 156,5 ; 162,8$. HRMS $\left(\mathrm{M}+\mathrm{Na}^{+}\right)$: calculado para $\mathrm{C}_{24} \mathrm{H}_{19} \mathrm{~F}_{3} \mathrm{~N}_{4} \mathrm{NaO}_{5}: 523,11998$; encontrado 523,12010. HRMS $\left(2 \mathrm{M}+\mathrm{Na}^{+}\right)$. calculado para $\mathrm{C}_{48} \mathrm{H}_{38} \mathrm{~F}_{6} \mathrm{~N}_{8} \mathrm{NaO}_{10}: 1023,25073$; encontrado: 1023,25087.

(1-(2-pirrolidina-5-(trifluorometil)fenil)-1H-1,2,3-triazol-4-il)metil 2-oxo-2H-benzopirano-3-carboxilato (35)

Sólido amarelo, obtido em $48 \%$ de rendimento, purificado por cromatografia em coluna de sílica gel eluída com hexano-acetato de etila $\left(1: 1 \mathrm{v} \mathrm{v}^{-1}\right)$, P.f. $=128,8-129,8{ }^{\circ} \mathrm{C}, \mathrm{R}_{\mathrm{f}}=0,46$. IV (ATR) $v_{\text {máx }} / \mathrm{cm}^{-1}: 3169,3060,2959,2854,2360,2161,2016,1980,1748$, 1698, 1607, 1564, 1526, 1459, 1375, 1331, 1270, 1242, 1213, 1553, 1097, 1084, 1034, 992, 956, 921, 883, 793, 772, 726, 705, 639, 589, $531,505,455$. RMN de ${ }^{1} \mathrm{H}\left(400 \mathrm{MHz}, \mathrm{CDCl}_{3}\right) \delta: 1,81-1,84(\mathrm{~m}, 4 \mathrm{H})$; $1,92(\mathrm{t}, 4 \mathrm{H}, J=6,6 \mathrm{~Hz}) ; 5,60(\mathrm{~s}, 2 \mathrm{H}) ; 6,89(\mathrm{~d}, 1 \mathrm{H}, J=8,8 \mathrm{~Hz}) ; 7,35-$ 7,39 (m, 2H); 7,43 (d, 1H, $J=1,6 \mathrm{~Hz}) ; 7,56(\mathrm{dd}, 1 \mathrm{H}, J=1,8 \mathrm{~Hz}$ e $J=9,0 \mathrm{~Hz}) ; 7,64-7,71(\mathrm{~m}, 2 \mathrm{H}) ; 8,02(\mathrm{~s}, 1 \mathrm{H}) ; 8,63(\mathrm{~s}, 1 \mathrm{H}) . \mathrm{RMN} \mathrm{de}$ ${ }^{13} \mathrm{C}\left(100 \mathrm{MHz}, \mathrm{CDCl}_{3}\right) \delta: 25,4 ; 49,0 ; 58,8 ; 115,4 ; 116,9 ; 117,3 ; 117,8 ;$ $118,1\left(\mathrm{q}, J_{C-F}=33,7 \mathrm{~Hz}\right) ; 121,5 ; 125,1 ; 125,5\left(\mathrm{q}, J_{C-F}=269,0 \mathrm{~Hz}\right)$; $126,9\left(\mathrm{q}, J_{C-F}=3,7 \mathrm{~Hz}\right) ; 127,8\left(\mathrm{q}, J_{C-F}=3,0 \mathrm{~Hz}\right) ; 128,3 ; 129,7 ; 134,8$; 142,$5 ; 146,5 ; 149,5 ; 155,3 ; 156,6 ; 162,6$. HRMS $\left(\mathrm{M}+\mathrm{Na}^{+}\right)$: calculado para $\mathrm{C}_{24} \mathrm{H}_{19} \mathrm{~F}_{3} \mathrm{~N}_{4} \mathrm{NaO}_{4}$ : 507,12506; encontrado 507,12517. HRMS $\left(2 \mathrm{M}+\mathrm{Na}^{+}\right)$: calculado para $\mathrm{C}_{48} \mathrm{H}_{38} \mathrm{~F}_{6} \mathrm{~N}_{8} \mathrm{NaO}_{8}$ : 991,26090; encontrado: 991,26098 .

(1-(2-piperidina-5-(trifluorometil)fenil)-1H-1,2,3-triazol-4-il)metil 2-oxo-2H-benzopirano-3-carboxilato (36)

Sólido branco, obtido com $51 \%$ de rendimento, purificado por cromatografia em coluna de sílica gel eluída com hexano-acetato de etila-diclorometano $\left(3: 1: 3 \mathrm{v} \mathrm{v}^{-1}\right)$, P.f. $=175,6-176,8^{\circ} \mathrm{C}, \mathrm{R}_{\mathrm{f}}=0,38 \mathrm{IV}$ (ATR) $v_{\text {máx }} / \mathrm{cm}^{-1}: 3156,3070,2944,2926,2824,2361,2161,2024$, 1980, 1947, 1743, 1714, 1607, 1565, 1516, 1468, 1382, 1328, 1301, 1265, 1233, 1208, 1178, 1100, 1081, 1024, 972, 897, 834, 794, 763, 722, 662, 638, 587, 521, 456. RMN de ${ }^{1} \mathrm{H}\left(400 \mathrm{MHz}, \mathrm{CDCl}_{3}\right)$ $\delta: 1,48-1,55(\mathrm{~m}, 6 \mathrm{H}) ; 2,72(\mathrm{t}, 4 \mathrm{H}, J=5,0 \mathrm{~Hz}) ; 5,62(\mathrm{~s}, 2 \mathrm{H}) ; 7,22$ $(\mathrm{d}, 1 \mathrm{H}, J=8,0 \mathrm{~Hz}) ; 7,34-7,38(\mathrm{~m}, 2 \mathrm{H}) ; 7,62-7,71(\mathrm{~m}, 3 \mathrm{H}) ; 7,84(\mathrm{~d}$, $1 \mathrm{H}, J=1,6 \mathrm{~Hz}) ; 8,54(\mathrm{~s}, 1 \mathrm{H}) ; 8,62(\mathrm{~s}, 1 \mathrm{H})$. RMN de ${ }^{13} \mathrm{C}(100 \mathrm{MHz}$, $\left.\mathrm{CDCl}_{3}\right) \delta: 23,8 ; 25,8 ; 52,0 ; 58,8 ; 116,9 ; 117,2 ; 117,7 ; 120,1 ; 124,1$ $\left(\mathrm{q}, J_{C-F}=3,7 \mathrm{~Hz}\right) ; 124,8\left(\mathrm{q}, J_{C-F}=33,5 \mathrm{~Hz}\right) ; 125,0 ; 125,8 ; 127,2$ $\left(\mathrm{q}, J_{C-F}=3,0 \mathrm{~Hz}\right) ; 129,7 ; 129,9 ; 134,8 ; 142,6 ; 149,4 ; 149,9 ; 155,3$; 156,$5 ; 162,5$. HRMS $\left(\mathrm{M}+\mathrm{Na}^{+}\right)$: calculado para $\mathrm{C}_{25} \mathrm{H}_{21} \mathrm{~F}_{3} \mathrm{~N}_{4} \mathrm{NaO}_{4}$ : 521,14071; encontrado 521,14081. HRMS $\left(2 \mathrm{M}+\mathrm{Na}^{+}\right)$: calculado para $\mathrm{C}_{50} \mathrm{H}_{42} \mathrm{~F}_{6} \mathrm{~N}_{8} \mathrm{NaO}_{4}$ : 1019,29220; encontrado: 1019,29223.

\section{Ensaios biológicos}

\section{Linhagem e cultivo}

Para a realização dos ensaios biológicos foi utilizada a linhagem celular U87MG de glioblastoma humano. As células foram mantidas em meio de manutenção - DMEM (high glucose) suplementado com $10 \%$ de soro fetal bovino, $1 \%$ de penicilina e estreptomicina, a $37{ }^{\circ} \mathrm{C}$, em atmosfera com $5 \%$ de $\mathrm{CO}_{2}$. Para a realização dos experimentos, as células foram plaqueadas a uma densidade de $1,5 \times 10^{4}$ células por poço, em placa de 96 poços.

\section{Solubilização dos compostos}

Os compostos 7-36 foram pesados e solubilizados em dimetilsulfóxido (DMSO) para preparo de uma solução estoque de $5000 \mu \mathrm{mol} \mathrm{L}{ }^{-1}$. A partir dela, foram preparadas soluções nas concentrações de 50, 100 e $150 \mu \mathrm{mol} \mathrm{L} \mathrm{L}^{-1}$ em meio de manutenção DMEM. ${ }^{49,50}$

\section{Ensaio de viabilidade celular pelo método MTT}

Os compostos 7-36 foram submetidos aos ensaios biológicos para avaliar seus efeitos sobre a linhagem U87MG de glioblastoma humano. O ensaio de viabilidade celular foi realizado empregando o método MTT. Tal método é fundamentado em uma análise colorimétrica baseada na conversão do sal amarelo brometo de 3-(4,5-dimetiltiazol-2-il)-2,5-difeniltetrazólio (MTT) no produto de coloração azul formazan, pela atividade da enzima succinildesidrogenase presente nas mitocôndrias e no citoplasma das células viáveis. Dessa forma, é possível quantificar a porcentagem de células metabolicamente ativas. ${ }^{51,52}$

Para a realização do ensaio, as células U87MG foram plaqueadas a uma densidade de $1,5 \times 10^{4}$ células/poço em placas de 96 poços e mantidas por $24 \mathrm{~h}$ em estufa a $37{ }^{\circ} \mathrm{C}$, em atmosfera umidificada a $5 \%$ de $\mathrm{CO}_{2}$. Posteriormente o meio de cultura foi substituído por meio contendo os compostos em diferentes concentrações $(50,100 \mathrm{e}$ $\left.150 \mu \mathrm{mol} \mathrm{L}{ }^{-1}\right)$. Os compostos 7-36 foram diluídos em DMEM com $10 \%$ de SFB em $0,4 \% \mathrm{v} \mathrm{v}^{-1}$ DMSO. Após 24,48 e $72 \mathrm{~h}$ de cultura, ${ }^{53}$ MTT $\left(0,5 \mathrm{mg} \mathrm{mL}^{-1}\right)$ foi adicionado a cada poço e incubado overnight a $37{ }^{\circ} \mathrm{C}$. A solução de MTT foi então removida e $100 \mu \mathrm{L}$ de DMSO foram adicionados por poço para solubilizar os cristais de formazan. Após 1 h, a leitura da absorbância foi medida no comprimento de onda de $530 \mathrm{~nm}$ em leitor de microplacas (VICTOR ${ }^{\mathrm{TM}}$ X3 da marca PerkinElmer). Os resultados foram normalizados considerando as culturas tratadas com $0,4 \% \mathrm{v} \mathrm{v}^{-1}$ de DMSO (controle). A viabilidade foi considerada $100 \%$ para o controle e os resultados submetidos às análises estatísticas pelo teste One-way ANOVA ( $p$ $\leq 0.05$ ) seguido pelo pós-teste de Tukey utilizando-se o Software GraphPadPrism, versão 5.0. Para a cultura de células, meio de cultura DMEM, solução de penicilina e estreptomicina, e tripsina $(0,25 \%)$ foram adquiridas da Sigma-Aldrich (St. Louis, MO, EUA). O soro fetal bovino foi adquirido da Cultilab (Campinas, Brasil). O corante MTT foi adquirido da Invitrogen (Eugene, OR, EUA). Dimetilsulfóxido (DMSO) foi adquirido da LGC Biotecnologia (Cotia, Brasil).

Os valores de absorbância foram obtidos e comparados à média dos controles celulares, considerados $100 \%$ viáveis. Foram realizados dois experimentos independentes em sextuplicata para cada concentração testada. Os valores de viabilidade referentes às diferentes concentrações dos compostos utilizados nos tratamentos foram submetidos às análises estatísticas pelo teste One-way ANOVA ( $\mathrm{p} \leq 0.05$ ) seguido pelo pós-teste de Tukey utilizando-se o Software GraphPadPrism, versão 5.0. 


\section{RESULTADOS E DISCUSSÃO}

\section{Síntese dos derivados 1,2,3-triazólicos}

A síntese da série de 1,2,3-triazóis inspirados no SRPIN340 teve início com a preparação dos nitrocompostos 2a-d, via reação de substituição nucleofílica aromática, empregando como material de partida o 1-fluoro-2-nitro-4-(trifluorometil)benzeno (1). ${ }^{36,54}$ $\mathrm{O}$ tratamento de $\mathbf{1}$ com diferentes aminas resultou na obtenção dos nitrocompostos com rendimentos variando de $85-95 \%$ (Esquema 1).<smiles>O=[N+]([O-])c1cc(C(F)(F)F)ccc1F</smiles>

(1)<smiles>[R7]c1ccc(C(F)(F)F)cc1[N+](=O)[O-]</smiles>

(2a-2d)
2a: $R_{1}=O \quad N-\xi-$
2c: $R_{1}=\longrightarrow N \cdot \xi$
2b: $\mathrm{R}_{1}=\mathrm{N}_{\mathrm{N}}-\mathrm{\xi}^{-}$
2d: $R_{1}=\square \mathrm{N}-\xi$

Esquema 1. Preparação dos nitrocompostos $2 \boldsymbol{a}-\mathbf{2 d}$

Em seguida, a redução dos nitrocompostos $\mathbf{2 a - 2 d}$ com $\mathrm{SnCl}_{2} /$ $\mathrm{HCl}$ levou à formação das aminas $\mathbf{3 a - 3 d}$ com rendimentos variando de $61-84 \%$ (Esquema 2). ${ }^{36,54}$<smiles>[R]c1ccc(C(F)(F)F)cc1[N+](=O)[O-]</smiles>

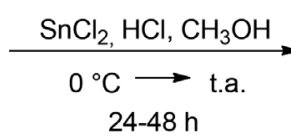

(2a-2d)<smiles>[R19]c1ccc(C(F)(F)F)cc1N</smiles>

$61-84 \%$
2a, 3a: $\mathrm{R}_{1}=\mathrm{O}^{\mathrm{N}-\xi^{-}}$
2c, 3c: $R_{1}=\longrightarrow N \cdot \xi$
2b, 3b R $\mathrm{R}_{1}=\longrightarrow \mathrm{N}-\mathrm{\xi}_{\mathrm{j}}$
2d, 3d: $R_{1}=\square N-\xi_{-}$

Esquema 2. Conversão dos nitrocompostos $\mathbf{2 a - d}$ nas aminas $\mathbf{3 a - 3 d}$

As aminas 3a-3d foram convertidas nos correspondentes sais de diazônio que foram, subsequentemente, tratados com azida de sódio, resultando na obtenção das azidas aromáticas 4a-4d (Esquema 3). ${ }^{55}$<smiles>[R7]c1ccc(C(F)(F)F)cc1N</smiles>

$(3 a-3 d)$

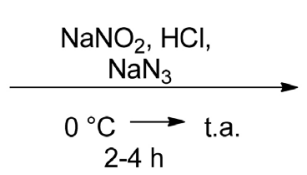<smiles>[Y5]NCCC</smiles>

Esquema 3. Preparação das azidas $\mathbf{4 a - 4 d}$
Para a obtenção dos derivados 1,2,3-triazólicos, os alcinos terminais mostrados no Esquema 4 foram preparados. Os compostos 5a-5g foram obtidos por meio da reação de catálise de transferência de fase entre diferentes álcoois benzílicos e o brometo de propargila. ${ }^{56,57}$ $\mathrm{O}$ tratamento da ftalimida com brometo de propargila em acetona/ $\mathrm{K}_{2} \mathrm{CO}_{3}$ levou à obtenção do derivado 5 h. Já o alcino 6 foi preparado em duas etapas, conforme mostrado no Esquema 4, a partir do salicilaldeído. ${ }^{58,59}$

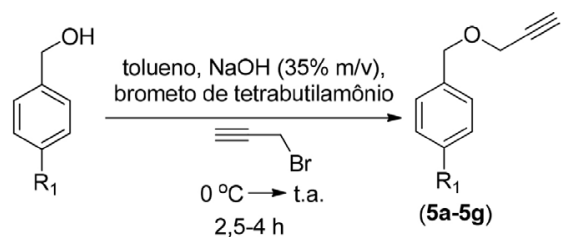

5a: $\mathrm{R}_{1}=4$-clorofenila $(74 \%)$

5b: $R_{1}=4$-metoxifenila $(76 \%)$

5c: $R_{1}=$ fenila $(52 \%)$

5d: $R_{1}=4$-bromofenila $(94 \%)$

5e: $R_{1}=4$-flurometilfenila $(78 \%)$

5f: $R_{1}=4-$ fluorofenila $(75 \%)$

5g: $R_{1}=4$-metilfenila $(79 \%)$
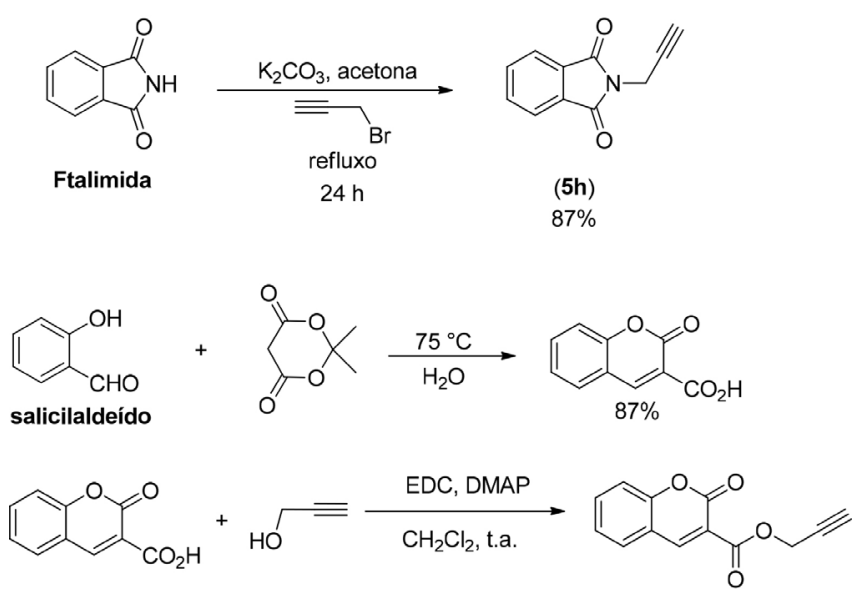

(6)

$57 \%$

Esquema 4. Preparação dos alcinos terminais 5 a-5h e 6

Uma vez preparados, os alcinos e as azidas foram utilizados em reações CuAAC (reações click) para a obtenção dos derivados 1,2,3-triazólicos (Esquema 5). ${ }^{60-64}$

Foi utilizada a combinação $\mathrm{CuSO}_{4}$ /ascorbato de sódio para realização das reações. Essa combinação gera $\mathrm{Cu}(\mathrm{I})$ in situ e que corresponde à espécie catalítica da reação. Os derivados foram obtidos com rendimentos de $31-91 \%$ e com tempos de reação variando de 30 minutos a 4 horas. Todos os compostos foram caraterizados por técnicas espectroscópicas (espectroscopias no infravermelho e de ressonância magnética nuclear) e espectrometria de massas de alta resolução. As estruturas das substâncias sintetizadas são mostradas na Figura 2.

Uma vez sintetizados, procedeu-se à avaliação dos efeitos destes compostos sobre a viabilidade da linhagem celular de glioblastoma humano (U87MG) pelo ensaio de MTT. Esse ensaio, baseado na redução do sal do brometo de tetrazólio, forneceu de forma quantitativa a porcentagem de células com atividade metabólica mitocondrial. Os ensaios de citotoxicidade in vitro apresentam vantagens, como a utilização de células humanas, que podem ser mais relevantes do que alguns testes em animais in vivo. ${ }^{65}$ Os resultados do efeito de todos os compostos testados em três diferentes concentrações (50, 100 e $150 \mu \mathrm{mol} \mathrm{L}^{-1}$ ) estão apresentados na Figura 3. Como os agentes 


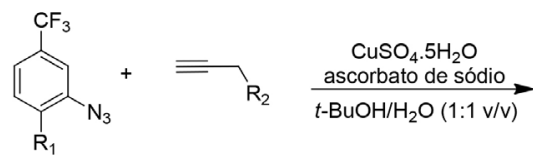<smiles>[R2]Cc1cn(-c2cc(C(F)(F)F)ccc2[R])nn1</smiles>

$31-91 \%$ $30 \mathrm{~min}-4 \mathrm{~h}$

$\mathrm{R}_{1}=$<smiles>CCN(CC)C(C)(C)C(C)(C)C</smiles>

$\mathrm{R}_{2}=$<smiles>Clc1ccc(COCCCCOCc2ccccc2)cc1</smiles><smiles>CCOCc1ccc(Br)cc1</smiles><smiles>CCOCc1ccc(OC)cc1</smiles><smiles>CCOCc1ccc(F)cc1</smiles>

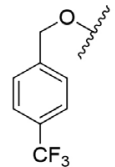<smiles>CC(C)CN1C(=O)c2ccccc2C1=O</smiles><smiles>CC(C)(C)OC(=O)c1cc2ccccc2oc1=O</smiles>

Esquema 5. Reação CuAAC utilizada na preparação dos 1,2,3-triazóis

químicos têm capacidade de afetar a viabilidade e o metabolismo das células, três tempos distintos foram estabelecidos para os ensaios. De fato, os resultados obtidos mostraram uma correlação da atividade dos compostos sobre a linhagem celular U87MG, de acordo com o tempo de exposição e a concentração utilizada nos tratamentos.

A análise dos resultados apresentados na Figura 3 revela que para o período de tratamento de $24 \mathrm{~h}$, os compostos que apresentaram efeitos sobre a linhagem celular U87MG foram 7, 15, 16, 17 e 34. Enquanto as substâncias 16 e $\mathbf{1 7}$ reduziram a viabilidade celular (aproximadamente 20\% de redução na concentração de $50 \mu \mathrm{mol} \mathrm{L}{ }^{-1}$ e cerca de $25 \%$ na maior concentração), os compostos 7, 15 e 34 aumentaram, respectivamente, a viabilidade em $68 \%, 24 \%$ e $45 \%$. O aumento da concentração potencializou esse efeito, com destaque para o derivado 7 que na maior concentração provocou aumento de $228 \%$ de viabilidade celular. Além disso, o composto 20, que não havia apresentado diferença significativa em relação ao controle na menor concentração, provocou aumento de $33 \%$ da viabilidade celular.

Quando o tempo de tratamento foi alterado de $24 \mathrm{~h}$ para $48 \mathrm{~h}$, observou-se um aumento do número de compostos, a saber, 11, 16-18, 21-27, 29, 31 e 32, capazes de reduzir a viabilidade celular (entre $16 \%$ e $31 \%$ de redução nas concentrações de 50 e $100 \mu$ mol L $\left.\mathrm{L}^{-1}\right)$. Com relação às substâncias 7, 15 e 34, que no período de $24 \mathrm{~h}$ aumentaram a viabilidade celular, observou-se que no período de $48 \mathrm{~h}$

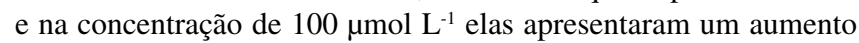
de cerca de $40 \%$ na viabilidade celular comparado ao período de tratamento de $24 \mathrm{~h}$. Interessantemente, na maior concentração e para o tempo de 48 h, esses compostos apresentaram ligeira redução na capacidade de aumentar a viabilidade comparado a concentração de $100 \mu \mathrm{mol} \mathrm{L}{ }^{-1}$. Ainda com relação ao período de $48 \mathrm{~h}$ de tratamento, deve ser mencionado que o composto 20, que não havia apresentado diferença estatística em relação ao controle na menor concentração, foi capaz de elevar a viabilidade celular na concentração de $100 \mu \mathrm{mol} \mathrm{L} \mathrm{L}^{-1}$, um comportamento similar ao observado para esse composto no período de $24 \mathrm{~h}$.

Com relação ao tempo de tratamento de $72 \mathrm{~h}$, notou-se que dos trinta compostos avaliados, vinte e oito apresentaram diferenças estatísticas significativas em relação ao controle para todas as
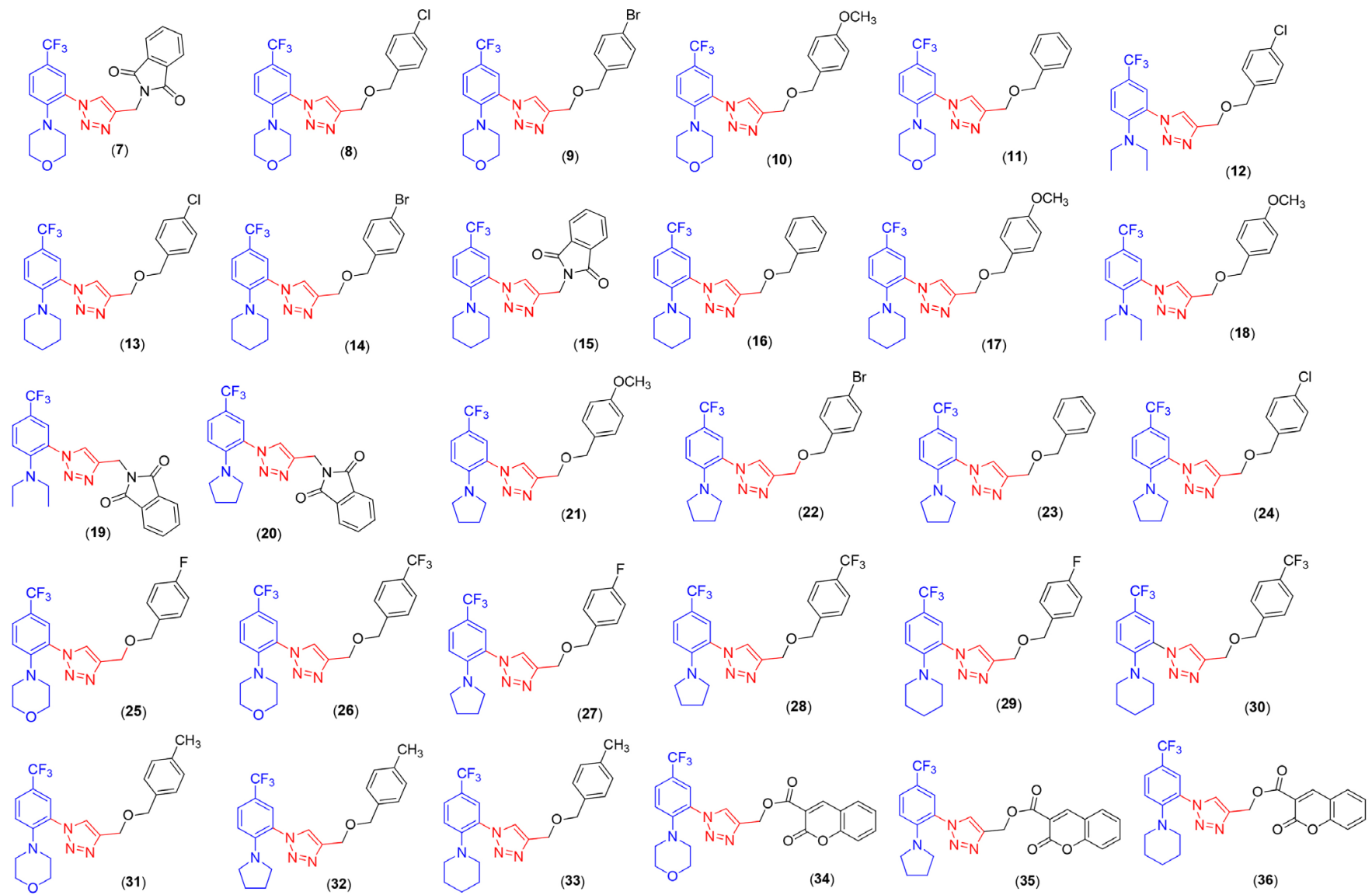

Figura 2. Estruturas dos derivados 1,2,3-triazólicos inspirados no SRPIN340. As porções destacadas em azul correspondem aos fragmentos 4-triflurometilfenil contendo substituintes amino enquanto que os destaques em vermelho correspondem às porções 1,2,3-triazólicas-1,4-dissubstituídas 

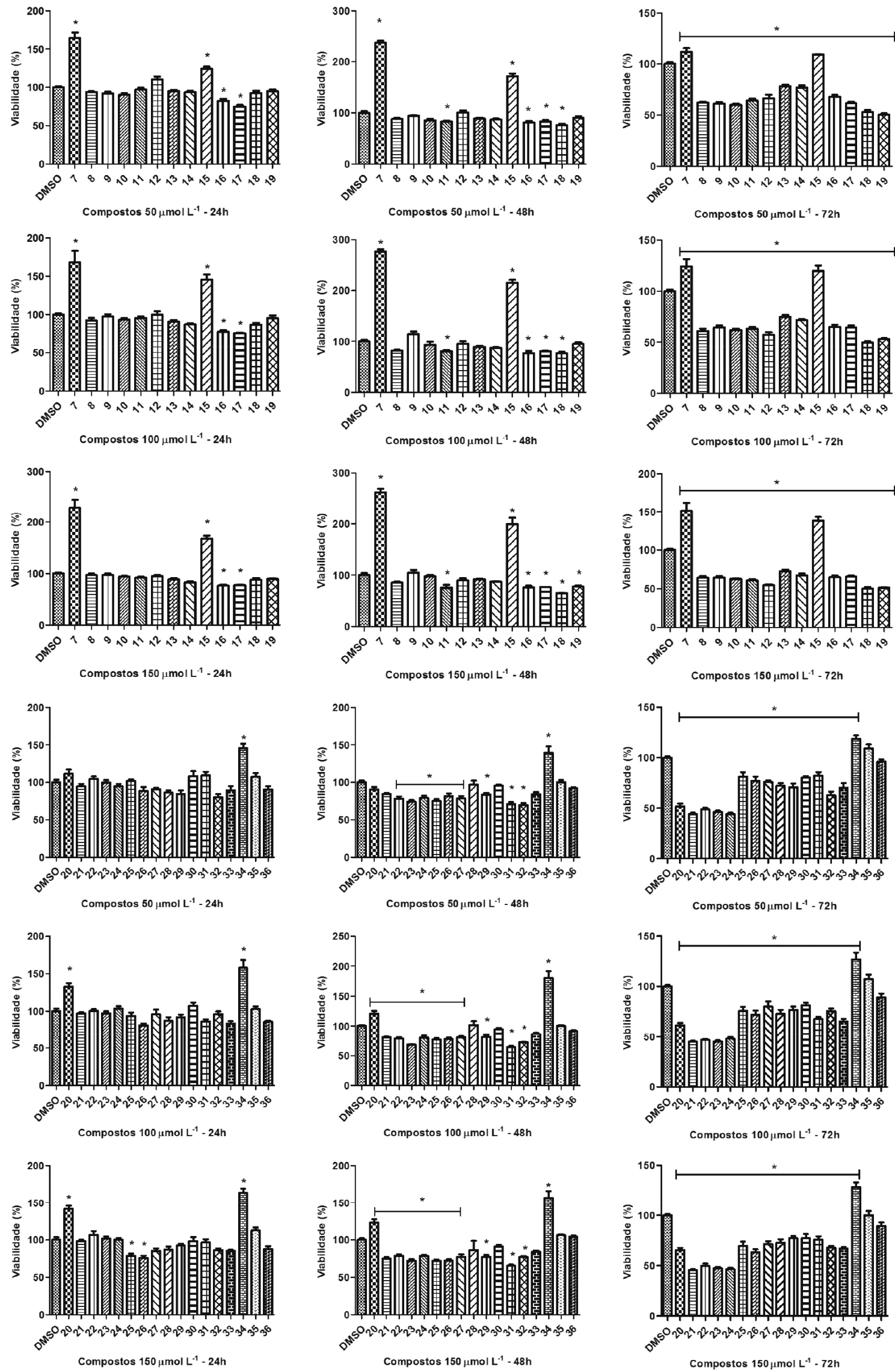

Figura 3. Resultados dos ensaios de avaliação dos efeitos dos compostos 7-36 sobre a linhagem celular U87MG. As substâncias foram avaliadas em três diferentes concentrações $\left(50,100\right.$ e $\left.150 \mu \mathrm{mol} \mathrm{L} L^{-1}\right)$ pelo ensaio de MTT. Os tempos de tratamento foram $24 \mathrm{~h}, 48 \mathrm{he} 72 \mathrm{~h}$. O asterisco (*) indica que os compostos apresentaram efeitos que foram estatisticamente diferentes do controle 
concentrações avaliadas. Os compostos 35 e 36 não apresentaram nenhum efeito sobre as células U87MG e para o restante dos vinte e oito compostos predominou o comportamento de redução de viabilidade celular. Os compostos 18, 19, 21, 23 e 24 reduziram a viabilidade em mais de $50 \%$.

Do ponto de vista de estrutura-atividade, os compostos 7, 15 e 34 apresentam como características estruturais comuns a presença das subunidades piperidinila ou morfolinila, além de grupos carbonilados (ftalimida e cumarina). Essas características estruturais parecem favorecer o potencial desses compostos em aumentar a viabilidade celular. Com relação às substâncias 18, 19, 21, 23 e 24, que diminuíram a viabilidade celular em mais de $50 \%$, elas apresentam como característica comum a presença de um grupo pirrolidinila ou dimetilamino.

Outro aspecto que deve ser destacado é que a marcante atividade de aumento de viabilidade celular exibida pelos compostos 7, 15 e 34 é atrativa, uma vez que essa bioatividade pode ser útil no desenvolvimento de substâncias com propriedades cicatrizantes. ${ }^{66-68}$

\section{CONCLUSÕES}

Utilizando o 1-fluoro-2-nitro-4-(trifluorometil)benzeno (1) como material de partida e uma rota sintética de cinco etapas, uma série inédita de trinta derivados 1,2,3-triazólicos inspirados no SRPIN340 foi preparada. De modo geral, as substâncias foram obtidas com bons rendimentos. Esses compostos foram avaliados frente à linhagem celular de glioblastoma U87MG. Concluiu-se que, enquanto os compostos 35 e 36 não apresentaram efeito sobre as células U87MG, para os demais compostos foram observados efeitos de diminuição e aumento da viabilidade celular. Os efeitos observados são dependentes tanto do tempo de tratamento bem como da concentração utilizada. Em termos de diminuição de viabilidade celular, os efeitos mais pronunciados foram observados para os compostos 18, 19, 21, 23 e $\mathbf{2 4}$, que na concentração de $150 \mu \mathrm{mol} \mathrm{L} \mathrm{L}^{-1}$ foram capazes de reduzir a viabilidade em mais de 50\%. Já para os compostos 7, 15 e 34 foram observados expressivos efeitos de aumento de viabilidade celular, que foram mais pronunciados para o tratamento de $48 \mathrm{~h}$. Acredita-se que essa última bioatividade possa ser utilizada no desenvolvimento de substâncias com propriedades cicatrizantes. Investigações com relação a essa possibilidade estão sendo realizadas e os resultados serão futuramente publicados.

\section{MATERIAL SUPLEMENTAR}

Todos os dados espectroscópicos utilizados neste trabalho estão disponíveis em http://quimicanova.sbq.org.br, na forma de arquivo PDF, com acesso livre.

\section{AGRADECIMENTOS}

À Coordenação de Aperfeiçoamento de Pessoal (CAPES) pela concessão de bolsa de estudo a SMRS.

\section{REFERÊNCIAS}

1. Ministério da Saúde; Instituto Nacional de Câncer José Alencar Gomes da Silva (INCA); ABC do câncer: abordagens básicas para o controle do câncer, $4^{\text {a }}$ ed. rev. atual, INCA: Rio de Janeiro, 2018.

2. Kumar, M. S.; Adki, K. M.; Biomed. Pharmacother. 2018, 105, 233.

3. Hassanpour, S. H.; Dehghani, M.; Journal of Cancer Research and Practice 2017, 4, 127.

4. American Cancer Society; Cancer Facts \& Figures 2021, American Cancer Society: Atlanta, 2021.
5. Wittekind, C.; Neid, M.; Oncology 2005, 69 (suppl. 1), 14.

6. https://ourworldindata.org/cancer, acessada em junho 2021.

7. Ferlay, J.; Colombet, M.; Soerjomataram, I.; Mathers, C.; Parkin, D. M.; Piñeros, Znaor, A.; Bray, F.; Int. J. Cancer 2019, 144, 1941.

8. INCA; Instituto Nacional do Câncer, disponível em: https://www.inca. gov.br, acessada em junho 2021.

9. Wogan, G. N.; Hecht, S. S.; Felton, J. S.; Conney, A. H.; Loeb, L. W.; Semin. Cancer Biol. 2004, 14, 473.

10. Louis, D. N.; Perry, A.; Reifenberger, G.; von Deimling, A.; FigarellaBranger, D.; Cavenee, W. K.; Ohgaki, H.; Wiester, O. D.; Kleihues, P.; Ellison, D. W.; Acta Neuropathol. 2016, 131, 803.

11. Goodenberger, M. L.; Jenkins, R. B.; Cancer Genet. 2012, $205,613$.

12. Omuro, A.; DeAngelis, L. M.; JAMA 2013, 6, 1842.

13. Chen, W.; Lei, C.; Liu, P.; Liu, Y.; Guo, X.; Kong, Z.; Wang, Y.; Dai, C.; Wang, Y.; Ma, W.; Wang, Y.; World Neurosurg. 2020, 134, e387.

14. Shepard, P. J.; Hertel, K.; Genome Biol. 2009, 10, 242.

15. Nikas, I. P.; Themistocleous, S. C.; Paschou, S. A.; Tsamis, K. J.; Ryu, H. S.; Cells 2020, 9, 19.

16. Gianakouros. T.; Nikolakaki, E.; Mylonis, I.; Georgatsou, E.; FEBS Journal 2011, 278, 570.

17. Zhang, Y.; Qian, J.; Gu, C.; Yang, Y.; Signal Transduction Targeted Ther. 2021, 6, 78.

18. Oltean, S.; Gammons, M.; Hulse, R.; Hamdollah-Zadeh, M.; Mavrou, A.; Donaldson, L.; Salmon, A. H.; Harper, S. J.; Ladomery, M. R.; Bates, D. O.; Biochem. Soc. Trans. 2012, 40, 831.

19. Qiu, Y.; Hoareau-aveilla, Cor.; Oltean, S.; Harper, S. J.; Bates, D. O.; Biochem. Soc. Trans. 2009, 37, 1207.

20. da Silva, M. R.; Moreira, G. A.; da Silva, R. A. G.; Barbosa, E. A. A.; Siqueira, R. P.; Teixeira, R. R.; Almeida, M. R.; Silva Júnior, A.; Fietto, J. L.; Bressan, G. C.; Biomed. Res. Int. 2015, 2015, 150514.

21. Pauli, F. P.; Barreiro, E. J.; Barbosa, M. L. C.; Rev. Virtual Quim. 2018, $10,1280$.

22. Ghosh, G.; Adams, J. A.; FEBS Journal 2011, $278,587$.

23. Sigala, I.; Tsamis, K. I.; Gousia, A.; Alexiou, G.; Voulgaris, S.; Giannakouros, T.; Kyritsis, A. P.; Nikolakaki, E.; Tumor Biol. 2016, 37, 8699.

24. Karakama, Y.; Sakamoto, N.; Itsui, Y.; Nakagawa, M.; Tasaka-Fujita, M; Nishimura-Sakurai, Y.; Kakinuma, S.; Oooka, M; Azuma, S.; Tsuchiya, K.; Onogi, H.; Hagiwara, M.; Watanabe, M.; Antimicrob. Agents Chemother. 2010, 54, 3179.

25. Oltean, S.; Gammons, M.; Hulse, R.; Hamdollah-Zadeh, M.; Mavrou, A.; Donaldson, L.; Salmon, A. H.; Hasper, S. J.; Ladomery, M. R.; Bates, D. O.; Biochem. Soc. Trans. 2012, 40, 831.

26. Fukuhara, T.; Hosoya, T.; Shimizu, S.; Sumi, K.; Oshiro, T.; Yoshinaka, Y.; Suzuki, M.; Yamamoto, N.; Herzenberg, L. A.; Hagiwara, M.; Proc. Natl. Acad. Sci. U. S. A. 2006, 103, 11329.

27. Gammons, M. V.; Fedorov, O.; Ivison, D.; Du, C.; Clark, T.; Hopkins, C.; Hagiwara, M.; Dick, A. D.; Cox, R.; Harper, S. J.; Hancox, J. C.; Knapp, S.; Bates, D. O.; Invest. Ophthalmol. Visual Sci. 2013, 54, 6052.

28. Dong, Z.; Noda, K.; Kanda, A.; Fukuhara, J.; Ando, R.; Murata, M.; Saito, W.; Hagiwara, M.; Ishida, S.; Mol. Vision 2013, 19, 536.

29. Takamatsu, Y.; Krähling, V.; Kolesnikova, L.; Halwe, S.; Lier, C.; Baumeister, S.; Noda, T.; Biedenkopf, N.; Becker, S.; mBio 2020, 11, e02565-19.

30. Morooka, S.; Hoshina, M.; Kii, I.; Okabe, T.; Kojima, H.; Inoue, N.; Okuno, Y.; Denawa, M.; Yoshida, S.; Fukuhara, J.; Ninomiya, K.; Ikura, T.; Furuya, T.; Nagano, T.; Noda, K.; Ishida, S.; Hosoya, T.; Ito, N.; Yoshimura, N.; Hagiwara, M.; Mol. Pharmacol. 2015, 88, 316.

31. Mavrou, A.; Brakspear, K.; Hamdollah-Zadeh, M.; Damodaran, G.; Babaei-Jadidi, R.; Oxley, J.; Gillatt, D. A.; Ladomery, M. R.; Harper, S. J.; Bates, D. O.; Oltean, S.; Oncogene 2015, 34, 4311.

32. Harper, S. J.; Bates, D. O.; Gammons, M.; Morris, J.; WO 2014060763 A1 20140424 2014; Harper, S. J.; Bates, D. O.; Gammons, M.; Morris, 
J.; WO 2019086478 A1 20190509 2019; Harper, S. J.; Bates, D. O.; Gammons, M.; Morris, J.; EP 3476949 A1 201905012019.

33. Moreaux, J.; De Boussac, H.; Kassambra, A.; WO 2019/086478 A1 2019; Moreaux, J.; De Boussac, H.; Kassambra, A.; EP3476949A1 2019.

34. Bressan, G. C.; Teixeira, R. R.; Silva Junior, A.; Fietto, J. L. R.; Lamêgo, M. R. A.; Neves, M. M.; Siqueira, R. P.; Moreira, G. A.; Lima, G. D. A.; Barros, M. V. A.; Viol, L. C. S.; Loterio, R. K.; Gonçalves, V. H. S.; Pereira, H. S.; Barbosa, E. A. A.; Br PI 102016029345 A2 20180717 2018.

35. Siqueira, R. P.; Barbosa, E. A. A.; Polêto, M. D.; Righetto, G. L.; Seraphim, T. V.; Salgado, R. L.; Ferreira, J. G.; Barros, M. V. A.; de Oliveira, L. L.; Laranjeira, A. B. B.; Almeida, M. R.; Júnior, A. S.; Fietto, J. L. R.; Kobarg, J.; de Oliveira, E. B.; Teixeira, R. R.; Borges, J. C.; Yunes, J. A.; Bressan, G. C.; PloS One 2015, 10, e0134882.

36. Siqueira, R. P.; Barros, M. V. A.; Barbosa, E. A. A.; Onofre, T. S.; Gonçalves, V. H. S.; Pereira, H. S.; Júnior, A. S.; de Oliveira, L. L.; Almeida, M. R.; Fietto, J. L. R.; Teixeira, R. R.; Bressan, G. C.; Eur. J. Med. Chem. 2017, 134, 97.

37. Moreira, G. A.; Lima, G. D. A.; Siqueira, R. P.; Barros, M. V. A.; Adjanohoun, A. L. M.; Santos, V. C.; Barbosa, E. A. A.; Loterio, R. K.; de Paiva, J. C.; Gonçalves, V. H. S.; Viol, L. C. S.; Marques-da-Silva, E. A.; Júnior, A. S.; Almeida, M. R.; Fietto, J. L.; Machado-Neves, M.; Ferreira, R. S.; Teixeira, R. R.; Bressan, G. C.; Toxicol. Appl. Pharmacol. 2018, 356, 214.

38. Teixeira, R. R.; da Silva, A. M.; Siqueira, R. P.; Gonçalves, V. H. S.; Pereira, H. S.; Ferreira, R. S.; Costa, A. V.; de Melo, E. B.; Paula, F. R.; Ferreira, M. M. C.; Bressan, G. C.; J. Braz. Chem. Soc. 2019, 30, 541.

39. Gazolla, P. A. R.; Teixeira, R. R.; da Silva, A. M.; Vaz, B. G.; Vasconcelos, G. A.; Siqueira, R. P.; Gonçalves, V. H. S.; Pereira, H. S.; Bressan, G. C.; Quim. Nova 2018, 41, 497.

40. Dheer, D.; Singh, V.; Shankar, R.; Bioorg. Chem. 2017, 71, 30.

41. Kharb, R.; Sharma, P. C.; Yar, M. S.; J. Enzyme Inhib. Med. Chem. 2011, $26,1$.

42. da Silva, F. C.; Cardoso, M. F. C.; Ferreira, P. G.; Ferreira, V. F. In Chemistry of 1,2,3-triazoles; Dehaen, W., Bakulev, V. A., eds.; SpringerVerlag: Berlin-Heidelberg, 2014.

43. Yan, J.; Lihui, S.; Lin, R.; Jin, H.; Jian, W.; Yu, Q.; Yang, S.; Eur. J. Med. Chem. 2019, 172, 62.

44. Ferroni, C.; Pepe, A.; Kim, Y. S.; Lee, S.; Guerrini, A.; Parenti, M. D.; Tesei, A.; Zamagni, A.; Cortesi, M.; Zaffaroni, N.; De Cesare, M.; Beretta, G. L.; Trepel, J. B.; Malhotra, S. V.; Varchi, G.; J. Med. Chem. 2017, 60, 3082.

45. Hu, H.; Zhang, A.; Ding, L.; Lei, X.; Zhang, L.; Molecules 2008, 13, 556.

46. dos Santos, N. A.; Ortiz, R. S.; Limberger, R. P.; Lacerda Júnior, V.; Romão, W; Orbital: Electron J. Chem. 2018, 10, 381.
47. Oliveira, B. G.; Pimentel, E. F.; Pereira, A. C. H.; Tosato, F.; Pinto, F. E.; Ventura, J. A.; Endringer, D. C.; Microchem. J. 2020, 153, 104391.

48. Oliveira, B. G.; Costa, H. B.; Ventura, J. A.; Kondratyuk, T. P.; Barroso, M. E. S.; Correia, R. M.; Pimentel, E. F.; Pinto, F. E.; Endringer, D. C.; Romão, W.; Food Chem. 2016, 204, 37.

49. Ribeiro, I. M. L.; Pereira, W. L.; Nogueira, L. B.; Oliveira, L. A. M.; Teixeira, R. R.; Nogueira, K. O. P. C.; Braz. Arch. Biol. Technol. 2020, 63, e20190072.

50. Teixeira, A. R.; Teixeira, R. R.; Ribeiro, I. M. L.; Pereira, W. L.; Manhabosco, T. M.; de Brito, A. C. F.; Oliveira, L. A. M.; Nogueira, K. Ol. P. C.; Toxicol. In vitro 2020, 68, 104970.

51. Mosman, T.; J. Immunol. Methods 1983, 65, 55.

52. Bernas, T.; Dobrucki, J.; Cytometry 2002, 47, 236.

53. de Almeida Lima, G. D.; Rodrigues, M. P.; Mendes, T. A. O.; Moreira, G. A.; Siqueira, R. P.; da Silva, A. M.; Vaz, B. G.; Fietto, J. L. R.; Bressan, G. C.; Machado-Neves, M.; Teixeira, R. R.; Toxicol. In vitro 2018, 53,1 .

54. Hagiwara, M.; Fukuhara, T.; Suzuki, M.; Hosoya, T.; US pat. 7,569,536 B2 2009.

55. Gill, C.; Jadhav, G.; Shaikh, M.; Kale, R.; Ghawalkar, A.; Nagargoje, D.; Shiradkar, M.; Bioorg. Med. Chem. Lett. 2008, 18, 6244.

56. Lucchese, A. M.; Marzorati, L.; Quim. Nova 2000, 23, 641.

57. Lima, A. M.; Teixeira, R. R.; da Silva, B. F.; Siqueira, R. P.; da Silva, I. E. P.; Santos, E. G.; Fernandes, M. C.; Gonçalves, V. H. S.; Bressan, G. C.; Mendes, T. A. O.; de Paula, S. O.; Costa, A.V. C.; dos Santos, M. H.; Quim. Nova 2019, 42, 473.

58. Cunha, S.; Iunes, C. E. M.; Oliveira, C. C.; Santana, L. L. B.; Quim. Nova 2015, 8, 1125.

59. Lutjen, A. B.; Quirk, M. A.; Barbera, A. M.; Kolonko, E. M.; Bioorg. Med. Chem. 2018, 26, 5291.

60. Freitas, L. B. O.; Ruela, F. A.; Pereira, G. R.; Alves, R. B.; Freitas, R. P.; Quim. Nova 2011, 34, 1791.

61. Gil, M. G.; Arévalo, M. J.; López, O.; Synthesis 2007, 1589.

62. Hou, J.; Liu, X.; Shen, J.; Zhao, G.; Wang, P. G.; Expert Opin. Drug Discov. 2012, 7, 489.

63. Kolb, H. C.; Sharpless, K. B.; Finn, M. G.; Angew. Chem., Int. Ed. 2001, 40, 2004.

64. Kolb, H. C.; Sharpless, K. B.; Drug Discov. Today 2003, 8, 1128.

65. Aslantürk, Ö. S. In Genotoxicity - A Predictable Risk to Our Actual World; Larramendy, M., Soloneski, S., eds.; IntechOpen, 2017.

66. Campos, A. C. L.; Borges-Branco, A; Groth, A. K.; Arq. Bras. Cir. Dig. 2007, 20, 51 .

67. Ustuner, O.; Anlas, C.; Bakirel, T.; Ustun-Alkan, F.; Sigirci, B. D.; Ak, S.; Akpulat, H. A.; Donmez, C.; Koca-Caliskan, U.; Molecules 2019, 24, 3353.

68. Agra, I. K. R.; Pires, L. L. S.; Carvalho, P. S. M.; Silva-Filho, E. A.; Smaniotto, S.; Barreto, E.; Ann. Acad. Bras. Cienc. 2013, 85, 945. 